UNIVERSIDADE DE SÃO PAULO

FACULDADE DE CIÊNCIAS FARMACÊUTICAS PROGRAMA DE PÓS-GRADUAÇÃO EM FARMÁCIA ÁREA DE ANÁLISES CLÍNICAS

\title{
TOXICIDADE E AÇÃO ANTITUMORAL DE UM DERIVADO DO QUIMIOTERÁPICO ETOPOSÍDEO (OLEATO DE ETOPOSÍDEO) ASSOCIADO A UMA MICROEMULSÃO RICA EM COLESTEROL
}

ANA CRISTINA LO PRETE

Dissertação para obtenção do grau de MESTRE

Orientador: Prof. Tit. Raul Cavalcante Maranhão 


\section{TOXICIDADE E AÇÃO ANTITUMORAL DE UM DERIVADO DO QUIMIOTERÁPICO ETOPOSÍDEO (OLEATO DE ETOPOSÍEO)ASSOCIADO A UMA MICROEMULSÃO RICA EM COLESTEROL}

Comissão Julgadora

Prof. Tit. Raul Cavalcante Maranháo

Orientador

Dr ${ }^{\mathrm{a}}$ Lígia Ferreira Gomes

$1^{\circ}$ Examinador

$\mathrm{Dr}^{\circ}$ Sergio Paulo Bydlowski

$2^{\circ}$ Examinador 


\section{DEDICATÓRIA}

A Deus, pela força durante a realização deste trabalho.

Aos meus amados pais Francisco e Sara, pelos ensinamentos de vida, amor e por sempre estarem ao meu lado acreditando e incentivando cada nova etapa de minha vida.

Aos meus irmãos Lúcia e Fábio, pelo amor, amizade e apoio.

Em especial ao meu irmão Francisco, pelo amor, ajuda desempenhada durante todo o trabalho e, acima de tudo, pela sua amizade.

Ao Fabrizio, pelo incentivo, amizade, amor e, principalmente, por me fazer feliz, a mais feliz. 


\section{Agradecimentos}

- Ao Prof. Titular Raul Cavalcante Maranhão pela indispensável orientação, oportunidade e apoio na minha formação científica.

- Ao Durvanei A. Maria, meu agradecimento por todo o apoio e ajuda, sem os quais não seria possível a realização deste trabalho.

- À Dra . Débora Garcia Rodrigues e Claudete Justina Valduga, pela ajuda e importante participação na minha formação profissional, além da valorosa amizade e apoio constante.

- Ao Dro. Ricardo Couto e à Denise Fernandes, meu agradecimento pela amizade, incentivo e críticas no período da realização deste trabalho.

- À minha amiga Carolina M. Heitmann, pela sincera amizade e companheirismo, o que tornou mais fácil a conclusão desta etapa.

- À toda equipe do Laboratório de Metabolismo de Lípides, em especial à Débora Deus.

- A todos os professores das disciplinas de pós-graduações, os quais foram de primordial importância de primordial importância para o meu crescimento pessoal e intelectual.

- A todos que, direta ou indiretamente, contribuíram para a realização deste trabalho com seu apoio prático, intelectual ou amizade. 


\section{SUMÁRIO}

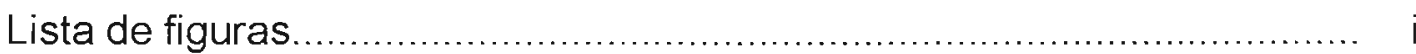

Lista de tabelas....................................................................

Lista de abreviações............................................................... iii

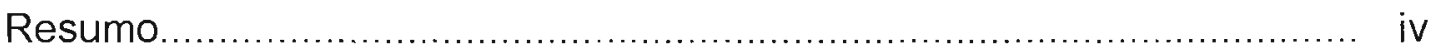

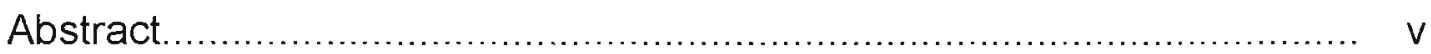

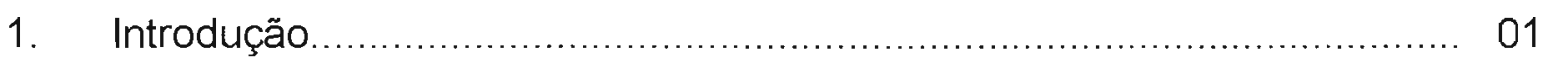

1.1 LDL e Câncer................................................................. 03

1.2 Microemulsões ricas em colesterol (LDE) e Câncer........................ 07

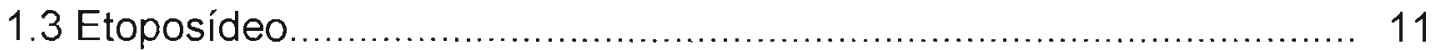

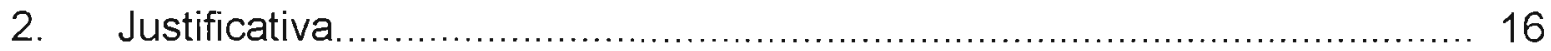

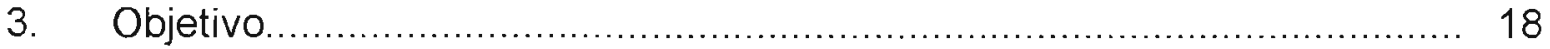

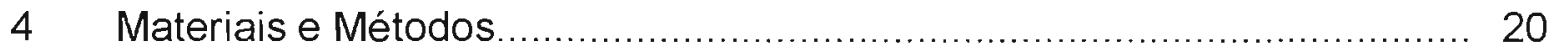

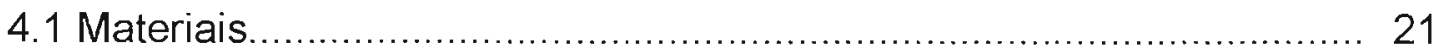

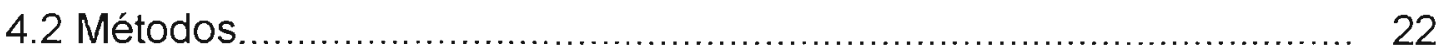

4.2.1 Preparo da LDE ...................................................... 22

4.2.2 Associação do oleato de etoposídeo à LDE ........................ 23

4.2.3 Estudos de toxicidade crônica....................................... 24

4.2.4 Estudos de toxicidade aguda........................................ 25

4.2.5 Implante de células de melanoma B16 F10 em Camundongos 25 C57BL/6J

4.2.6 Avaliação do efeito antitumoral. 26 
4.2.7 Análise Estatística.

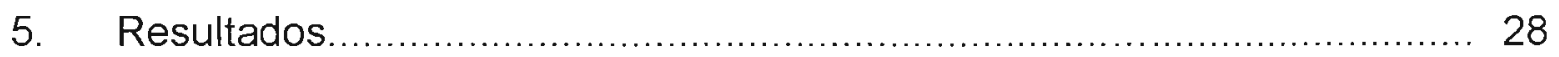

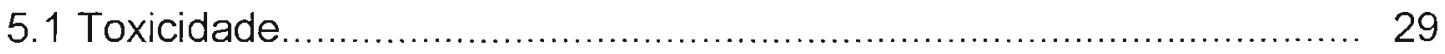

5.1.1 Toxicidade crônica...................................................... 29

5.1 .2 Toxicidade aguda............................................. 32

5.2 Atividade antitumoral ......................................................... 33

5.2.1 Efeito sobre o crescimento do tumor de melanoma B16......... 33

$5.2 .2 \%$ de sobrevivência dos animais................................. 38

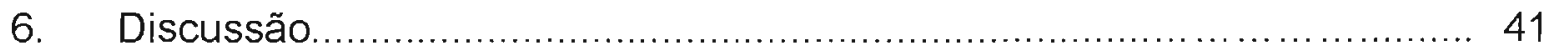

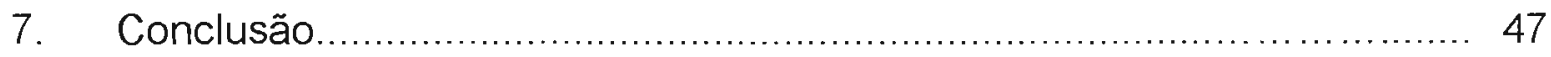

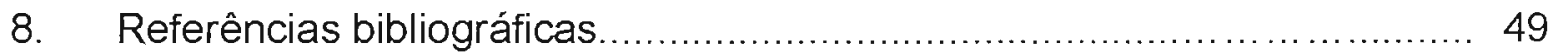




\section{LISTA DE FIGURAS}

Figura 1. Estrutura da Podofilotoxina e seus derivados de uso clínico.

Figura 2. Curvas das médias diárias das variações de peso dos camundongos após injeção em dose única de etoposídeo em sua formulação comercial nas doses de 25,50 e $75 \mathrm{mg} / \mathrm{kg}$.

Figura 3. Curvas das médias diárias das variações de peso dos camundongos após injeção em dose única da associação LDE-oleato de etoposídeo nas doses de 150, 200 e $250 \mathrm{mg} / \mathrm{kg}$.

Figura 4. Crescimento da massa de tumor de melanoma B16 em grupos de camundongos tratados com as formulações de LDE-oleato de etoposídeo 10 $\mathrm{mg} / \mathrm{kg}$, LDE-oleato de etoposídeo $50 \mathrm{mg} / \mathrm{kg}$, etoposídeo comercial $10 \mathrm{mg} / \mathrm{kg}$ e solução de $\mathrm{NaCl} 0,9 \%$.

Figura 5. Volume tumoral em animal do grupo etoposídeo comercial $10 \mathrm{mg} / \mathrm{kg}$ no $16^{\circ}$ dia e no $25^{\circ}$ dia.

Figura 6. Volume tumoral em animal do grupo LDE-oleato de etoposídeo 10 $\mathrm{mg} / \mathrm{kg}$ no $16^{\circ}$ dia e no $25^{\circ}$ dia.

Figura 7. Volume tumoral em animal do grupo controle no $16^{\circ}$ dia e no $25^{\circ}$ dia.

Figura 8. Volume tumoral em animal do grupo LDE-oleato de etoposídeo 50 $\mathrm{mg} / \mathrm{kg}$ no $16^{\circ}$ dia e no $25^{\circ}$ dia.

Figura 9. Porcentagem de sobrevivência dos camungongos tratados com as formulações LDE-oleato de etoposídeo e etoposídeo comercial, em mesma dosagem de $10 \mathrm{mg} / \mathrm{kg}$, e solução controle $(\mathrm{NaCl}$ 0,9\%), após inoculação de tumor de melanoma B16. 
Figura 10. Porcentagem de sobrevivência entre camundongos tratados com a formulação LDE-oleato de etoposídeo, nas dosagens de 10 e $50 \mathrm{mg} / \mathrm{kg}$, e solução controle ( $\mathrm{NaCl}$ 0,9\%), após inoculação de tumor de melanoma B16. 


\section{LISTA DE TABELAS}

Tabela 1 - Determinação das doses letais 10,50 e 90 em camundongos fêmeas C57BL/6J, após administração por via intraperitoneal das formulações: etoposídeo comercial, LDE-oleato de etoposídeo e LDE.

Tabela 2 - Atividade antitumoral de LDE-oleato de etoposídeo (10 e 50 mg/kg) vs etoposídeo em sua formulação comercial $(10 \mathrm{mg} / \mathrm{kg})$ no modelo de melanoma B16 implantando em camundongos C57Bl/6J. 


\section{LISTA DE ABREVIATURAS}

APO

LDL

VLDL

HDL

IDL

rLDL

$\mathrm{pH}$

HMG CoA redutase

ACAT

LMA

LDE

VP 16-213

PBS

c.p.m

UI

IC 50

DL
Apolipoproteína

Lipoproteína de baixa densidade

Lipoproteína de densidade muito baixa

Lipoproteina de alta densidade

Lipoproteína de densidade intermediária

Receptor de LDL ou Receptor B/E

Potêncial hidrogeniônico

3-hidroxi-3-metilglutaril Co A redutase

Acil Co A: colesterol aciltransferase

Leucemia mielocítica aguda

Emulsão rica em colesterol

Etoposídeo

Tampão Fosfato

Contagens por minuto

Unidade internacional

Índice de citotoxicidade $50 \%$

Dose letal

Dose máxima tolerada 
$\mathrm{CL}$

Vdss

$\mathrm{T} 1 / 2$

$\mathrm{mSv}$
Clearance

Volume de Distribuição

Tempo de meia vida

Milisievert 


\section{RESUMO}

LO PRETE, A. C. Toxicidade e ação antitumoral de um derivado do quimioterápico etoposídeo (oleato de etoposídeo) associado a uma microemulsão rica em colesterol. São Paulo, 2004. Faculdade de Ciências Farmacêuticas da Universidade de São Paulo.

Ao utilizar uma microemulsão lipídica artificial rica em colesterol (LDE), como transportador de fármacos antineoplásicos, é possivel aumentar a dose administrada com redução dos efeitos tóxicos. Quando injetada na circulação, a LDE liga-se aos receptores da lipoproteína de baixa densidade (rLDL). Grande parte das células neoplásicas apresenta aumento da expressão dos rLDL, permitindo aumento da concentração da LDE e do fármaco nestes tecidos. Recentemente, o quimioterápico etoposídeo foi associado à LDE através de uma modificação em sua estrutura, sem alterar o efeito citotóxico do fármaco e sendo captado via rLDL.

Neste estudo, deu-se continuidade a esta linha, realizando os estudos pré-clínicos, em camundongos, da associação LDE-oleato de etoposídeo. Foram realizados estudos de toxicidade crônica e toxicidade aguda, tendo sido determinadas as doses máximas toleradas (DMT) e doses letais (DL) da LDE-oleato de etoposídeo em comparação com o fármaco comercial. A DMT para a formulação LDE-oleato de etoposideo é oito vezes maior do que a encontrada para o etoposídeo comercial, enquanto a $D L_{50}$ é 5,4 vezes menor, o que demonstra uma redução significativa da toxicidade do fármaco após a modificação e associação à LDE.

No mesmo modelo animal, foi comparada a eficácia antitumoral das formulações de LDE-oleato de etoposídeo e etoposídeo comercial, através da observação da evolução do crescimento tumoral e porcentagem de sobrevivência. A associação LDE-oleato de etoposídeo mostrou-se mais efetiva em retardar o crescimento tumoral, assim como promoveu aumento da taxa de sobrevida quando, comparado ao etoposideo comercial. Dessa forma, a associação LDE-oleato de etoposídeo aumentou o índice terapêutico do fármaco. 


\section{SUMMARY}

When using a cholesterol-rich microemulsion (LDE), as an antineoplastic drug transporter, it is possible to increase the administered dose and reduce its side effects. When injected in the circulation, LDE binds to the low density lipoprotein receptors (LDLr). Most of the neoplastics cells has LDLr overexpressed, what leads to LDE and drug concentration in these tissues. Recently, the etoposide was associated to LDE through a modification in its structure, without changing the drug cytotoxic effect and being uptaken by rLDL..

This study follows up the LDE-etoposide oleate development, through in mice pre-clinical studies. Chronic toxicity and acute toxicity studies were accomplished to determinate the maximum tolerated doses (MTD) and lethal doses (DL) of LDE- etoposide oleate comparing with the commercial drug. The LDE-etoposide oleate MTD is 8-fold higher than the commercial etoposídeo, while $\mathrm{DL}_{50}$ is 5,4 -fold lower, resulting in a significant reduction of the drug toxicity after the modification and association to LDE.

In the same animal model, it was compared the antitumoral activity effectiveness of the LDE-etoposide oleate and commercial etoposide, through the observation of the growth tumoral inhibition and survival percentage. The association LDE- etoposide oleate showed to be more effective in inhibit the tumoral growth and promoted increase of the median survival as compared to the commercial etoposide. In conclusion, the association LDE-etoposide oleate increased the therapeutic index of the drug. 
Novos agentes quimioterapicos são testados anualmente e tem-se alcançado o controle para certas formas de câncer. Porém, a quimioterapia geralmente provoca toxicidade acentuada em diversos órgãos. Os efeitos agudos mais freqüentes são náusea, vômito, cefaléia e perda de apetite. Como efeito subagudo pode ocorrer mielossupressão, comprometendo os sistemas imunológico e hematológico. Como efeito tardio pode ocorrer toxicidade hepática, renal, pulmonar e cardíaca, além do desenvolvimento de neoplasias secundárias. Desta forma, o objetivo maior da quimioterapia é a destruição seletiva das células malignas, sem que os órgãos e tecidos normais sejam afetados pelos intensos efeitos colaterais dos fármacos antineoplásicos.

Estudos vêm sendo realizados com a finalidade de aumentar a especificidade dos quimioterápicos às células tumorais, empregando-se vários veículos, como polímeros (KAN et al., 1990), lipossomas, (TYAGI et al., 1997; BELLOTT et al., 2001), que são vesículas de fosfolipídeos com meio aquoso no interior, lipossomas carregados positivamente (SENGUPTA et al., 2000), hormônios, anticorpos (JUNGHANS et al., 1996), emulsões lipídicas (MARANHÃO et al., 1986; LUNDBERG, 1994) e enzimas.

Nas duas últimas décadas, vários autores têm trabalhado na possibilidade de utilização das lipoproteínas de baixa densidade (LDL), partículas que transportam a maior parte do colesterol circulante no plasma humano, para dirigir fármacos antitumorais às células neoplásicas. Isto se baseia nas evidências de que as células neoplásicas apresentam um aumento no número de receptores de LDL (HO et al., 1978), como conseqüência da maior demanda de colesterol para a síntese de novas membranas. 
A comprovação de que o número de receptores para a LDL em células tumorais se encontra aumentado abriu um novo campo de pesquisa: a utilização da LDL como transportadora de quimioterápicos (GAL et al., 1981; RUDLING et al., 1983; MASQUELIER et al., 1986; LUNDBERG et al., 1987; TOKUI et al., 1995; SMIDT et al., 1990)

\subsection{LDL E CÂNCER}

As lipoproteínas podem ser classificadas em quatro grupos de acordo com sua densidade: quilomícrons, lipoproteina de baixa densidade (LDL), lipoproteína de densidade muito baixa (VLDL) e lipoproteína de alta densidade (HDL).

A LDL resulta do catabolismo da VLDL, lipoproteína sintetizada no fígado e que sofre a ação da lipase lipoprotéica. Esta enzima catalisa a hidrólise dos triglicerídeos e diglicerídeos da VLDL, transformando-a em partículas menores, progressivamente mais pobres em triglicerídeos e mais densas, sendo a LDL o produto final deste processo.

O núcleo apolar da LDL é formado principalmente de ésteres de colesterol que constituem quase a metade do peso da lipoproteína, contendo também uma pequena proporção de triglicerídeos. A parte protéica da LDL é constituída praticamente apenas de uma única molécula de apolipoproteína B-100, que é o componente que liga essas partículas a receptores específicos. A LDL 
ligada aos receptores é então captada através de um processo de endocitose e é degradada pelos lisossomos (GOLDSTEIN et al., 1985), possibilitando a utilização do colesterol em vários processos celulares, entre eles, a síntese de membranas e hormônios.

Os receptores de LDL (rLDL) são regulados pela concentração intracelular de colesterol. Quando esta concentração está elevada, ocorre diminuição da atividade da enzima 3-hidroxi-3-metilglutaril CoA redutase. A HMG CoA redutase é a enzima que catalisa a etapa chave da biossíntese de colesterol. Ocorre ainda redução da expressão dos rLDL. Finalmente, o excesso de colesterol intracelular ativa a ação da enzima acil CoA: colesterol aciltransferase (ACAT) que esterifica o colesterol e o estoca em forma de gotículas (BILHEIMER, 1988). Quando as células estão deficientes de colesterol ocorre, em resposta, aumento de expressão dos rLDL e aumento da atividade da HMG CoA redutase. O rLDL está sujeito a "feedback" (regulação retroativa) e sua regulação é o principal fator para o controle da concentração plasmática de LDL (GOLDSTEIN et al., 1990).

De início, verificou-se baixos níveis de lipoproteínas plasmáticas em pacientes com leucemia mielocítica aguda (BASES et al, 1965; MILLER et al., 1981), assim como em outros tumores malignos, em relação a um grupo de indivíduos normais (NYDEGGER et. al., 1972). Posteriormente, observou-se diminuição dos níveis plasmáticos de colesterol total e LDL em pacientes com mieloma múltiplo (HUNGRIA et. al., 1995).

Em trabalho realizado por $\mathrm{HO}$ et al (1978), foram evidenciadas uma maior captação e metabolização de LDL em células mononucleares sangüíneas de pacientes com leucemia mielóide aguda. A solução de LDL foi marcada com ${ }^{125} \mathrm{I}$, e 
mostrou captação de três a 100 vezes maior por células leucêmicas, quando comparadas às células de indivíduos saudáveis. Este aumento é conseqüência da necessidade extrema de fornecimento de lipídios para a síntese de novas membranas devido à sua alta capacidade proliferativa.

A avaliação da atividade de captação de LDL em tumores cerebrais primários e metastáticos, removidos cirurgicamente e comparados com tecido cerebral normal adjacente foi realizada em 1990 por RUDLING et al. O estudo foi feito por meio de incubação de macerados homogeneizados de tumor e de cérebro normal com LDL marcada com ${ }^{125}$. A taxa de captação da LDL foi maior no tecido tumoral em comparação com o tecido normal.

Todos esses relatos se devem ao fato da maior necessidade da célula tumoral em usar o colesterol da LDL para a formação de novas membranas para as células em divisão. Por conseqüência, vemos um aumento do número de receptores para LDL nessas células, condição esta que possibilitou o uso da LDL como transportadora de quimioterápicos às células alvo, diminuindo assim a toxicidade aos demais órgãos (RUDLING et al., 1986; VALLABHAJOSULA et al., 1989, 1990; VITOLS et al., 1990; SMIDT et al., 1990).

Em seqüência a esses achados, VITOLS et al (1992) realizaram estudos comparativos de captação de LDL entre células de tumores pulmonares e de tecido pulmonar normal adjacente. LDL marcada foi administrada em pacientes com carcinoma de pulmão sem tratamento prévio e que seriam submetidos à cirurgia. Medindo-se a radioatividade no tumor e no tecido normal, observou-se que esta foi três vezes maior no tecido tumoral, quando comparada ao pulmão normal.

Em 1996, foi estudado o metabolismo da LDL e seu papel na 
distribuição seletiva de fármacos antineoplásicos, usando como modelo ratos portadores de melanoma B16. Foi mostrado que a solução de LDL marcada é absorvida pela célula tumoral por meio de reação mediada por receptores na qual a degradação intracelular da lipoproteína envolve a participação de lisossomas (VERSLUIS et al., 1996).

Geralmente, o tratamento com quimioterápicos ocasiona efeitos colaterais graves, comprometendo a função de diversos órgãos (GOODMAN \& GILMAN, 2001). Portanto, o tratamento ideal seria aquele em que as células neoplásicas fossem alvos específicos dos quimioterápicos, atingindo o mínimo possível os tecidos normais. No entanto, o uso deste sistema ainda encontra-se restrito às experiências de laboratório. A dificuldade da utilização da LDL na prática pode ser atribuída à dificuldade de isolamento por plasmaferese e alterações em sua estrutura durante a sua manipulação para incorporação de fármacos. Além disso, por se tratar de um hemoderivado, a LDL pode provocar respostas imunológicas, bem como provocar contaminação por vírus da hepatite, HIV e outros.

Uma alternativa ao uso de LDL humana é a utilização de emulsões lipídicas artificiais com estrutura semelhante à mesma e com a propriedade de se ligar aos receptores da LDL. 


\subsection{MICROEMULSÕES RICAS EM COLESTEROL (LDE) E CÂNCER}

MARANHÃO et al (1986) realizaram estudos de metabolismo da LDL através de uma micromicroemulsão lipídica, a LDE, com composição semelhante à fase lipídica da LDL, constituída de aproximadamente $66 \%$ de fosfolipídeos, $33 \%$ de colesterol-éster e $1 \%$ de triglicerídeos, sem a parte protéica da lipoproteína (HIRATA, 1991), micromicroemulsão esta que seria utilizada na investigação da hipercolesterolemia relacionada à aterosclerose.

Experimentos para verificar o comportamento da LDE foram conduzidos em indivíduos normolipidêmicos e portadores de hipercolesterolemia, condição esta em que ocorre acúmulo de colesterol devido à deficiência nos rLDL. Foi verificado que a remoção da LDE no último grupo era mais lenta do que no grupo de indivíduos normais, confirmando que a mesma poderia ser utilizada como instrumento para investigação das dislipidemias (MARANHÃO et al., 1997). Isso constitui uma evidência de que a LDE é removida pelos receptores de $L D L$, visto que nesta patologia há um defeito em tais receptores (BROWN et al., 1986), justificando a lenta remoção da LDE.

Os resultados preliminares de estudos conduzidos em ratos mostraram que a LDE apresentava cinética plasmática semelhante à da LDL natural, sugerindo que estivesse sendo captada pelos mesmos receptores da LDL. A LDE não contém a apo B, no entanto, foi descoberto que é capaz de adquirir outra lipoproteína, a apo E, do plasma (MARANHÃO et al., 1993). É importante ressaltar que a LDL natural não possui apo E, ligando-se ao receptor através da sua única proteína, a apo B100. 
Estudos de competição em linfócitos mostraram que a LDL natural compete com LDE pela captação celular, comprovando que a remoção de ambas se dá pelo mesmo receptor específico (MARANHÃO et al., 1997). No entanto, a LDE tem maior afinidade pelos receptores de LDL do que a LDL natural (HIRATA et al., 1999). Isto acontece porque a apo $\mathrm{E}$ apresenta maior afinidade pelos receptores do que a apo B100.

Por ser obtida artificialmente, a LDE não apresenta os riscos relacionados com a utilização de hemoderivados, proporcionando a realização de estudos para comprovar a expressão aumentada e afinidade dos rLDL pela LDE em diversos tipos de tumores humanos.

Com os elementos disponíveis sobre o comportamento da LDE, foi levantada a hipótese de que a LDE pode substituir a LDL natural como veículo para direcionar os quimioterápicos para os tecidos malignos, evitando órgãos e tecidos normais (MARANHÃO et al., 1993; MARANHÃO et al., 1994). Os quimioterápicos seriam incorporados à $L D E$, a qual seria injetada na circulação, adquirindo a apo $E$, e então, se ligaria preferencialmente aos receptores para LDL das células neoplásicas, os quais estariam em número muito maior comparativamente às células normais. Desta forma a LDE aumentaria a eficiência do tratamento quimioterápico ao mesmo tempo em que reduziria seus efeitos colaterais.

Esta hipótese foi comprovada primeiramente em pacientes com leucemia mielocítica aguda (LMA). Nesse estudo, verificou-se que a LDE foi removida com velocidade muito maior nos pacientes com LMA do que nos controles. Além disso, após os pacientes serem tratados com esquemas quimioterápicos convencionais e atingida completa remissão da doença, a remoção plasmática da 
Introdução

LDE tornava-se mais lenta, normalizando-se. Isto mostra que as células LMA, com rLDL em número muito maior, provocaram remoção acelerada da micromicroemulsão. Naquele trabalho, também foi mostrada a captação da LDE pela medula óssea infiltrada de células LMA de maneira direta, através de imagens de Medicina Nuclear obtidas com LDE marcada com Tecnécio ${ }^{99 m}$. Trata-se de uma experiência de "targeting" sem precedentes na literatura, já que, conforme demonstraram os estudos cinéticos, $66 \%$ da LDE injetada foi captada pelas células leucêmicas (MARAINHÃO et al., 1994).

Em experimentos posteriores, foram confirmadas a captação e concentração da LDE em tumor sólido, como no carcinoma de mama e suas metástases (GRAZIANI et al., 1995) e em tecido maligno de ovário (ADES et al., 2001). Pela primeira vez, foi possível direcionar um veículo feito artificialmente para o tecido neoplásico.

A especificidade da associação para as células neoplásicas foi também demonstrada em experimentos, realizados "in vitro", com daunorrubicina associada à LDE, havendo morte de $46,7 \%$ das células blásticas neoplásicas e $20,2 \%$ das células normais da medula óssea (DORLHIAC-LAACER et al., 2001).

Recentemente utilizou-se a LDE como transportadora do quimioterápico paclitaxel (RODRIGUES et al., 2002). O paclitaxel apresentou alta taxa de incorporação à LDE, sendo que a citotoxicidade da LDE-paclitaxel foi seis vezes menor que a do paclitaxel em sua formulação comercial $\left(\operatorname{Taxol}{ }^{\circledR}\right)$. A redução do efeito citotóxico ocorreu devido à ausência do Cremophor EL, usado como veículo do paclitaxel na preparação comercial. A toxicidade letal dessa associação em ratos foi dez vezes menor que a do Taxol ${ }^{\circledast}$. 
Outro quimioterápico de ação antineoplásica incorporado à LDE foi a carmustina. Foram estudadas a estabilidade da associação e a integridade química do fármaco após a incorporação, determinando-se a sua biodistribuição e toxicidade em rato. Foi verificado que a associação com a carmustina não altera o direcionamento da LDE para os seus sítios de ligação específicos. Através de estudos de incubação com células normais e de linhagens neoplásicas verificou-se que, quando associada à LDE, a carmustina não perde a sua ação citotóxica (MARANHÃO et al., 2002).

O tratamento convencional com carmustina causa sistematicamente forte mielotoxicidade, principalmente leucopenia e plaquetopenia, acentuada e tardia. Esses efeitos são cumulativos, de tal forma que a administração continuada do fármaco é limitada. O seu uso também pode levar à fibrose pulmonar e insuficiência renal. Os estudos em pacientes com tumor sólido avançado, resistente ao tratamento convencional com carmustina, mostraram que a associação deste fármaco com a LDE diminui os efeitos colaterais da quimioterapia (MARANHÃO et al., 2002).

Subseqüentemente, em um grupo de pacientes com mieloma múltiplo ainda não tratados, foi possivel aquilatar melhor a ação terapêutica da associação LDE-carmustina, administrado em dose de $180 \mathrm{mg} / \mathrm{m}^{2}$ de superfície corpórea do fármaco. Além da nítida melhora clínica da amostragem de sete pacientes, os ríveis de imunoglobulina $M$, secretada pelas células do mieloma, marcador bioquímico mais importante da doença, decresceram em mais de $60 \%$, sem que tenha havido efeitos colaterais importantes (HUNGRIA et al., 2003).

Em estudos desenvolvidos com oleato de etoposídeo associado à 
partícula de micromicroemulsão, observou-se que a modificação química (introdução de um grupo oleila), aumentando a lipofilicidade do fármaco, não alterou sua citotoxicidade e, além disso, elevou de 50 para aproximadamente $98 \%$ a taxa de incorporação à LDE. A citotoxicidade da associação LDE-oleato de etoposídeo para a linhagem celular H 292 (células não-pequenas de pulmão) foi em torno de duas vezes menor que a formulação comercial, sendo que essa diferença é atribuída à toxicidade do veículo, na preparação comercial (VALDUGA et al., 2003).

\subsection{ETOPOSÍDEO}

Extratos de mandrágora americana (Podophyllum peltatum e Podophyllum emodi) têm sido utilizados terapeuticamente por mais de 200 anos. Em 1946, King e Sullivan descobriram as propriedades antimitóticas da podofilo. Greenspan et al; Leiter et al (1950) demonstraram por análises químicas que a podofilo apresenta uma série de compostos, incluindo a podofilotoxina que possui toxicidade proibitiva, impedindo seu uso na terapêutica (CHAKRAVORTY et al, 1967; VAITKEVICIUS \& REED, 1966). Vários derivados da podofilotoxina foram sintetizados como o etoposídeo e o teniposide, largamente utilizados no tratamento do câncer (KELLER-JUSTIN et al., 1971). Após quatro décadas, o etoposídeo continua sendo utilizado como fármaco de primeira linha no tratamento de câncer de células pequenas e não pequenas de pulmão, tumores de células germinativas, linfomas de Hodgkin e não Hodgkin, leucemia aguda não linfocítica, câncer de 
ovário, mama e gástrico (GOODMAN \& GILMAN, 2001).

Etoposídeo tem uma estrutura complexa com multianéis da podofilotoxina ligados a um açúcar, o glucopiranosídeo. Ele difere da podofilotoxina por apresentar um centro glucosídeo no átomo C-4, na configuração enantiomérica da epodofilotoxina, e apresenta ainda um grupo hidróxi na posição C-4 ao invés de um grupo metoxi.

Na figura 1 está representada a estrutura da podofilotoxina (1) e seus congêneres em uso clínico, os fármacos etoposídeo (2a), fosfato de etoposídeo (2b) e teniposide (2c)<smiles>COc1cc([C@H]2c3cc4c(cc3[C@@H](O)C3COC(=O)[C@H]32)OCO4)cc(OC)c1OC</smiles>

1

Podofilotoxina

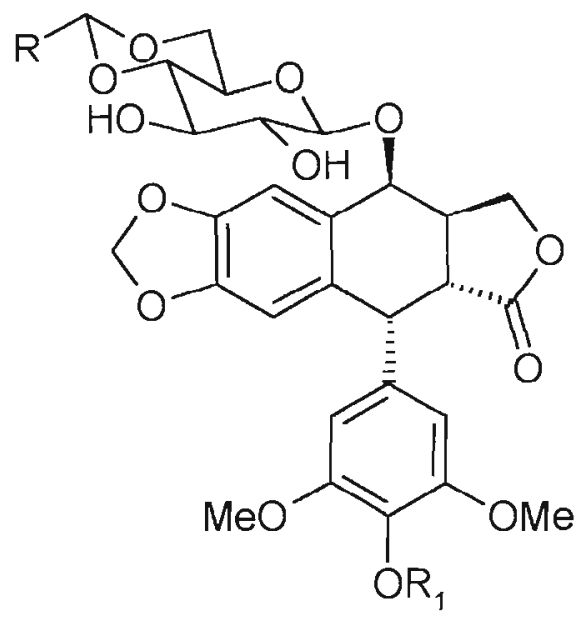

2

$$
\begin{array}{ll}
\text { 2a } & \mathrm{R}=\mathrm{CH}_{3}, \mathrm{R}_{1}=\mathrm{H} \text { (etoposide) } \\
\text { 2b } & \mathrm{R}=\mathrm{CH}_{3}, \mathrm{R}_{1}=\mathrm{PO}(\mathrm{OH})_{2} \text { (fosfato de etoposide, etopos) } \\
\text { 2c } & \mathrm{R}=\mathrm{R}_{\mathrm{S}}=\mathrm{H} \text { (teniposide) }
\end{array}
$$

Figura 1. Estrutura da Podofilotoxina e seus derivados de uso clinico. 
O etoposídeo (C29H32O13) tem peso molecular de 588 e é quimicamente descrito como 4'-o-dimetil-1-o-(4,6-o-etilideno-ß-d-glicopiranosil) epipodofilotoxina, sendo conhecido como VP 16-213. A forma cis-lactona do etoposídeo (picro-etoposídeo) mostro-se inativa em estudo realizado por Kalwinsky et al. (1982). Em outro estudo, esta mesma forma foi 100 vezes menos potente na fase G2 do ciclo celular (DOW et al., 1983).

O etoposídeo induz um bloqueio no ciclo celular (STAHELIN, 1973) e é mais citotóxico na fase $\mathrm{S}$ tardia (síntese de DNA), ou inicial da fase G2 (intervalo pré-mitótico) in vivo e in vitro, sendo assim fármaco citotóxico de fase específica. $\mathrm{O}$ etoposídeo causa quebras nas fitas duplas e simples do DNA sendo dosedependente; produz ainda "cross-links" (ligações cruzadas de proteínas) e aberrações cromossomais. A quebra da fita de DNA devido à formação de um complexo ternário com a enzima topoisomerase-Il é provavelmente o efeito inicial das seqüências biossintéticas e cinéticas que leva à citotoxicidade. A enzima permanece ligada à extremidade livre do filamento quebrado de DNA, levando a propagação de quebras do DNA e conseqüente morte celular (GOODMAN \& GILMAN, 2001).

O etoposídeo é muito solúvel em metanol e clorofórmio, sendo pouco solúvel em etanol, água e éter. Apresenta-se mais miscível em água quando combinado a solventes orgânicos. Devido a essa característica, o etoposídeo possui formulação comercial (por mL): 20 mg de etoposídeo, 2,0 mg de ácido cítrico, 30 mg de álcool benzílico, $80 \mathrm{mg}$ de polissorbato modificado (Tween 80), $650 \mathrm{mg}$ de polietilenoglicol 300 e $30,5 \%(v / v)$ de etanol.

A estabilidade do etoposídeo em soluções é variável, dependendo da 
concentração de sais e do pH. É mais estável em pH 5,0 e em soluções mais ácidas é degradado em aglicona.

No que diz respeito à farmacocinética do etoposídeo, estudos mostram que após administração intravenosa, o fármaco possui tempo de meia vida na fase de eliminação (t1/2 $\beta$ ) em torno de 6 horas, volume de distribuição de 7 a $17 \mathrm{~L} / \mathrm{m}^{2}$ em adultos e clearance (depuração plasmática) total variável entre 15 e $35 \mathrm{~mL} / \mathrm{min} / \mathrm{m}^{2}$. Aproximadamente 20 a $45 \%$ do etoposídeo são excretados na urina inalterados, indicando que o rim é o principal responsável pela excreção do fármaco (PETER et al., 1987)

Pacientes fazendo uso do etoposídeo têm como efeitos agudos náusea e vômito. Os efeitos tardios são alopécia e mielossupressão, sendo a granulocitopenia predominante.

Para reduzir os efeitos colaterais do etoposídeo, estudos com a utilização de transportadores vêm sendo desenvolvidos. A exemplo disso, a utilização de fármacos lipossomais tem sido alvo de pesquisas de direcionamento de agentes antineoplásicos a tumores sólidos (GABIZON et al., 1985). De fato, em 1998 foi demonstrado que a longa circulação de lipossomas estabilizados poderiam aumentar a eficácia antitumor e reduzir a toxicidade do etoposídeo (SENGUPTA et al., 1998). Esse mesmo grupo de trabalho relatou recentemente que a incorporação do etoposídeo em lipossomas catiônicos aumentou a eficácia antitumor e reduziu a toxicidade do fármaco, em comparação com a formulação convencional (SENGUPTA et al., 2000). Foi demonstrado também que a encapsulação em lipossomas catiônicos, de fato, aumenta o tempo de depuração plasmática do etoposídeo e a área sob a curva (AUC), indicando com isso uma maior tempo na 
circulação.

Recentemente o etoposídeo foi associado à LDE, após modificação química para torná-lo mais lipofílico. Essa modificação promove aumento na taxa de incorporação do fármaco na LDE em relação ao não modificado, visto que o etoposídeo apresentou taxa de incorporação de $50 \%$ contra $98 \%$ do oleato de etoposídeo. Foi verificado que a associação é estável em meio aquoso e a estabilidade pós-preparação tem duração de 6 dias. A taxa de dissociação da partícula é de $10 \%$ nesse período. Os resultados de incubação com células indicam que a associação LDE-oleato de etoposídeo tem atividade antiproliferativa sobre células da linhagem neoplásica NCI H292 (VALDUGA et al., 2003). 
Trabalhos anteriores realizados com a associação da LDE-carmustina e LDE-paclitaxel demonstraram que a LDE é um veículo promissor para o direcionamento de fármacos de ação antineoplásica, diminuindo a toxicidade dos mesmos.

Em estudos recentes verificou-se que a taxa de incorporação do etoposídeo à LDE foi baixa. Tendo em vista o uso clínico da preparação, a lipofilicidade do fármaco foi aumentada pela introdução do grupo oleíla, obtendo-se assim o oleato de etoposídeo, que possibilitou um aumento da taxa de incorporação de 50 para 98\%. A associação LDE-oleato de etoposídeo mostrou-se bastante estável, manteve a atividade citotóxica do fármaco e não alterou o mecanismo de captação da LDE.

Dando seqüência a este trabalho, é necessário verificar através de estudos de toxicidade crônica e toxicidade aguda, a dose máxima tolerada e as doses letais para a associação LDE-oleato de etoposídeo, comparando estes índices com os do fármaco em sua formulação comercial. É importante também verificar a efetividade da associação em reduzir a velocidade de crescimento do tumor, assim como em aumentar a porcentagem de sobrevivência animal, em comparação ao etoposídeo comercial. Esses dados são fundamentais para a realização dos ensaios clínicos da LDE-oleato de etoposideo. 
$\checkmark$ Determinar a toxicidade crônica e a toxicidade aguda da associação LDEoleato de etoposídeo e comparar com o etoposídeo comercial, em camundongos sadios.

$\checkmark$ Verificar em modelo oncológico murino a eficácia antitumoral da associação LDE-oleato de etoposídeo em comparação à do etoposídeo comercial. 
4. MATERIAIS E MÉTODOS 


\subsection{MATERIAIS}

Os lipídeos trioleína (TG), oleato de colesterol (CO) e colesterol (CL) utilizados na produção das emulsões a partir de soluções-estoque, foram adquiridos da Nu-Check Prep. Elisian, EUA. A fosfatidilcolina (FL) foi obtida da Lipid Products (Surrey, Inglaterra).

Toda a vidraria utilizada durante os experimento foi submetida a esterilização a seco (estufa a $180^{\circ} \mathrm{C}$, por $1 \mathrm{~h}$ e $30 \mathrm{~min}$ ) e a vapor (autoclavagem a $120^{\circ} \mathrm{C}, 1 \mathrm{~atm}, 20 \mathrm{~min}$ ), procedimento este realizado pelo Setor de Esterilização do Instituto do Coração do Hospital das Clínicas da Faculdade de Medicina da Universidade de São Paulo (Incor-HC-FMUSP).

O Oncosídeo ${ }^{\circledR}$ (etoposídeo em sua formulação comercial) e seu veículo foram doados pela Indústria Farmacêutica Quiral Química do Brasil (Juiz de Fora, MG, Brasil).

Nos experimentos em questão foram utilizados camundongos isogênicos C57BL/6J fêmeas, com peso minimo $20 \mathrm{~g}$. O critério de escolha do sexo foi baseado em experimentos realizados anteriormente, em mesmo laboratório, onde os camundongos fêmeas responderam de forma mais uniforme ao tratamento. Para os estudos de eficácia antitumoral foi utilizado um modelo de tumor murino, melanoma B16 F10. Os camundongos, assim como o modelo tumoral, foram cedidos pelo Departamento de Imunogenética do Instituto Butantã (São Paulo, Brasil). 
4.2 MÉTODOS

\subsubsection{Preparo da LDE}

A micromicroemulsão LDE foi preparada segundo a técnica descrita por MARANHÃO et al (1993). A mesma foi preparada a partir da mistura de $40 \mathrm{mg}$ de fosfatidilcolina, $20 \mathrm{mg}$ de colesterol oleato, $1 \mathrm{mg}$ de trioleína, e $0,5 \mathrm{mg}$ de colesterol livre, dissolvidos em clorofórmio-etanol $(2: 1 \mathrm{v} / \mathrm{v})$. Os lipídios foram pipetados em frasco de vidro. A seguir, as misturas foram secas sob fluxo de nitrogênio, em banho de água $\left(37^{\circ} \mathrm{C}\right)$ e mantidas em dessecador a vácuo, por $16 \mathrm{hs}$, a $4^{\circ} \mathrm{C}$, para a remoção total dos solventes residuais. Ao final desse tempo, se adicionou $10 \mathrm{ml}$ de tampão TRIS-HCl $0,01 \mathrm{M}, \mathrm{pH} 8,0$, à mistura dessecada. A seguir, a suspensão de lipídios foi emulsificada por irradiação ultrassônica durante 3hs, sob atmosfera de nitrogênio, com temperatura variando entre 51 e $55^{\circ} \mathrm{C}$, na qual os componentes estão em estado de transição cristal-liquído, controlada por termômetro digital inserido diretamente no frasco de vidro. A irradiação ultrassônica foi realizada com uma potência de 125 watts, em modo contínuo de operação por um disruptor de células Branson, modelo B 450 (Arruda Ultrassom, São Paulo, SP), equipado com ponta de titânio $1 \mathrm{~cm}$ de diâmetro.

Ao término da irradiação ultrassônica as microemulsões foram purificadas por ultracentrifugação (Ultracentrifuga Sorvall, modelo OTD Comb, Wilmington, EUA) equipada com rotor TH 641, durante 30 minutos, a $35000 \mathrm{rpm}$, a $4^{\circ} \mathrm{C}$. O sobrenadante da solução $(1,0 \mathrm{ml})$, contendo partículas que flotam em 
densidade $1,006 \mathrm{~g} / \mathrm{ml}$, foi retirado e descartado. O volume restante foi submetido a nova ultracentrifugação a $35000 \mathrm{rpm}$, durante $2 \mathrm{hs}$, a $4^{\circ} \mathrm{C}$, após adição de brometo de potássio sólido, para ajustar a densidade em 1,210 g/ml. Do sobrenadante foram removidos $2,0 \mathrm{ml}$, os quais contém a fração das partículas de tamanho e composição desejados.

A micromicroemulsão purificada foi dialisada utilizando-se $4,0 \mathrm{ml}$ de tampão estéril TRIS-HCI 0,01 M, pH 8,0, e saco de diálise Spectrapor 6 (Spectrum Medical Ind., Los Angeles, EUA), por $16 \mathrm{hs}$, a $4^{\circ} \mathrm{C}$, para a total remoção dos sais de brometo de potássio utilizados na etapa final de purificação. A micromicroemulsão purificada foi submetida à esterilização por filtração em filtros com poros de $0,2 \mu$ de diâmetro (Millipore, São Paulo, SP).

Todo o procedimento de preparo das microemulsões foi realizado em câmara de fluxo laminar vertical, para evitar contaminação por microorganismos. Essas microemulsões foram submetidas a testes de esterilidade na Seção de Bacteriologia do Laboratório do Hospital das Clínicas da Faculdade de Medicina da Universidade de São Paulo e pirogenicidade "in vivo" no Instituto de Medicina Nuclear da Universidade de São Paulo.

\subsubsection{Associação do oleato de etoposídeo à LDE}

O oleato de etoposídeo, sintetizado conforme método descrito por VALDUGA et al. (2003), foi associado à LDE numa razão 10:1, em massa de lipídios:fármaco, por se tratar da proporção mais estável de associação (dados não 
publicados). O etoposídeo foi dissolvido em $300 \mu \mathrm{L}$ de etanol e misturado com 3,0 $\mathrm{mL}$ de LDE. A associação foi realizada utilizando-se irradiação ultrassônica, com potência de 125 Watts, por 40 minutos a $55^{\circ} \mathrm{C}$ em banho de água/gelo. A fração do fármaco que não se associou a LDE foi separada por centrifugação. Foi utilizado no experimento apenas o etoposídeo associado à LDE. As preparações foram esterilizadas em filtro Millipore $0,22 \mu \mathrm{m}$ e realizadas no mesmo dia do experimento.

\subsubsection{Estudos de toxicidade crônica}

Os estudos de toxicidade crônica foram realizados segundo protocolo estabelecido por ZHANG et. al. (1997). Para tanto, foram utilizados camundongos C57BCL/6J fêmeas, pesando entre 20-25g, com idade de 2 a 3 meses. Os animais foram mantidos no Biotério de Imunogenética do Instituto Butantã em sala com temperatura controlada e acesso livre à ração e água.

Grupos de 8 camundongos receberam doses únicas, por via intraperitoneal, das preparações: LDE-oleato de etoposídeo nas doses de 150, 200 e $250 \mathrm{mg} / \mathrm{kg}$, etoposídeo comercial nas doses de 25,50 e $75 \mathrm{mg} / \mathrm{kg}$ e o volume de LDE correspondente as doses de 200 e $250 \mathrm{mg} / \mathrm{kg}$ de LDE-oleato de etoposídeo. Todas as doses foram ajustadas com base no peso corpóreo.

Medidas do peso do animal foram tomadas diariamente por um período de 15 dias. Observações diárias da sobrevida dos animais foram feitas durante mesmo período.

A dose máxima tolerada (DMT) correspondeu à dose onde não houve morte ou perda de peso corpóreo superior a 15\% em nenhum animal do grupo. 


\subsubsection{Estudos de Toxicidade Aguda}

Seguindo-se a norma descrita por Zhang (1997), para os estudos de toxicidade aguda foram utilizados camundongos C57BCL/6J fêmeas, mantidos em biotério, como descrito anteriormente. Grupos de 5 camundongos receberam doses únicas, por via intraperitoneal, das preparações: LDE-oleato de etoposídeo nas doses de 100, 150, 200, 250 e $500 \mathrm{mg} / \mathrm{Kg}$, etoposídeo comercial nas doses de 25, $50,75,100$ e $150 \mathrm{mg} / \mathrm{kg}$ e o volume de LDE correspondente as doses de 200 e 250 $\mathrm{mg} / \mathrm{kg}$ de LDE-oleato de etoposídeo. Todas as doses foram ajustadas com base no peso corpóreo.

Observações diárias da sobrevida dos animais foram feitas durante 30 dias. $\mathrm{A} \mathrm{DL}_{10}, \mathrm{DL}_{50}$ e $\mathrm{DL}_{90}$, que representam a dose letal responsáveis pela morte de 10, 50 e $90 \%$ dos animais, respectivamente, foram calculadas através de interpolação dos resultados obtidos (porcentagem de morte no grupo $\mathrm{x}$ doses).

\subsubsection{Implante de células de melanoma B16 F10 em Camundongos C57BL/6J}

Tumores originários de células de melanoma B16 foram mantidos através de transplantes seriados em camundongos fêmeas C57BL/6J. Para a manutenção do modelo, tecidos tumorais foram retirados periodicamente e transplantados em outro grupo de camundongos através de método padrão. Após excisado, o tecido tumoral foi macerado em solução fisiológica estéril $\left(9 \mathrm{mg} / \mathrm{mL}^{-1}\right)$, filtrado e centrifugado a 1000 rpm por 8 minutos. O sobrenadante foi então eliminado 
e o "pellet" ressuspenso em $1 \mathrm{~mL}$ de solução salina. Desta solução retirou-se uma alíquota, posteriormente diluída 100 vezes, para contagem das células neoplásicas viáveis. Esta contagem foi feita em câmara de Neubauer utilizando-se o corante azul de trypan, o qual cora a membrana celular das células viáveis. Aproximadamente $100 \mu \mathrm{L}$ contendo $5 \times 10^{4}$ células viáveis em solução de fosfato tamponada foram injetadas subcutaneamente na região dorsal de camundongos fêmeas. Em média, 10 dias após a inoculação os tumores podiam ser visualizados macroscopicamente.

\subsubsection{Avaliação do efeito antitumoral}

O efeito antitumoral do fármaco foi verificado seguindo o protocolo estabelecido pelo Instituto Nacional do Câncer (PLOWMAN et al., 1997). Foram analisadas a medida da massa tumoral e a porcentagem de sobrevivência de camundongos C57BCL/6J fêmeas com implante de tumor de melanoma B16.

Após desenvolvimento do tumor de melanoma B16 com possivel visualização macroscópica (11 dias após inoculação), foi injetado intraperitonealmente soluções de LDE-oleato de etoposídeo (10 e 50 mg/Kg), etoposídeo comercial $(10 \mathrm{mg} / \mathrm{Kg}$ ) e solução de cloreto de sódio 0,9\% (controle). As soluções foram administradas em 3 doses no $11^{\circ}, 13^{\circ}$ e $15^{\circ}$ dia, a contar da data de inoculação do tumor. Todas as preparações corresponderam a grupos de 15 animais.

Os animais tiveram seus tumores medidos com o auxílio de um paquímetro. A medição foi feita a cada 2 (dois) dias, após a data de início do tratamento, durante 14 dias. 
Para tumores implantados por via subcutânea, a massa do tumor (em miligramas; mm) é estimada a partir do seu diâmetro, sendo calculada de acordo com a expressão (GERAN et al., 1972):

\section{Comprimento $(\mathrm{mm}) \times[$ largura $\mathrm{mm})]^{2}$}

Massa Tumoral $(\mathrm{mg})=$

Observações diárias da sobrevida dos animais foram feitas durante 45 dias (FREIREICH et al., 1966).

\subsubsection{Análise estatística}

Foi calculada a área sob a curva nos ensaios de avaliação da modulação do crescimento do tumor para verificar o efeito dos tratamentos no crescimento tumoral em função do tempo. Para obtenção desses resultados utilizamos o programa Gpip (Graphpad Inplot, Version 4.0). A análise dos dados, onde se comparou dois ou mais grupos com distribuição não paramétrica foi feita utilizando-se a análise de variância (ANOVA) seguida do teste de comparação múltipla de TUKEY-KRAMER.

Todos os valores foram expressos em média \pm desvio médio, considerando-se como nível crítico para significância valores $<0,05$. 
5.1 TOXICIDADE

\subsubsection{Toxicidade crônica}

A DMT foi estimada como a dose em que não houve morte ou perda de peso superior a $15 \%$ em nenhum animal no grupo. Foram determinadas as DMT's de LDE, LDE-oleato de etoposídeo e etoposídeo comercial em camundongos fêmeas C57BL/6J.

A Figura 2 mostra as curvas das variações de peso dos animais do grupo etoposídeo comercial. Pudemos observar que nas doses de 50 e $75 \mathrm{mg} / \mathrm{kg}$ houve morte ou perda de peso superior a $15 \%$. Contudo, na dose de $25 \mathrm{mg} / \mathrm{kg}$, não observamos nenhum desses efeitos, sendo esta dose estabelecida como DMT da formulação etoposídeo comercial. Na Figura 2 também se observa que os animais do grupo etoposídeo comercial não recuperaram seu peso iricial durante o período de observação (15 dias).

As curvas de variação de peso dos animais que receberam doses de 150, 200 e 250 mg/kg da formulação LDE-oleato são mostradas na Figura 3. A DMT de LDE-oleato de etoposídeo foi $200 \mathrm{mg} / \mathrm{kg}$, visto que ocorreram mortes de animais na dose de $250 \mathrm{mg} / \mathrm{kg}$. Com relação à recuperação de peso dos animais, foi observado que os animais pertencentes ao grupo de dose 150 e $200 \mathrm{mg} / \mathrm{kg}$ da LDEoleato de etoposídeo recuperavam seu peso inicial após 8 e 9 dias, respectivamente. 


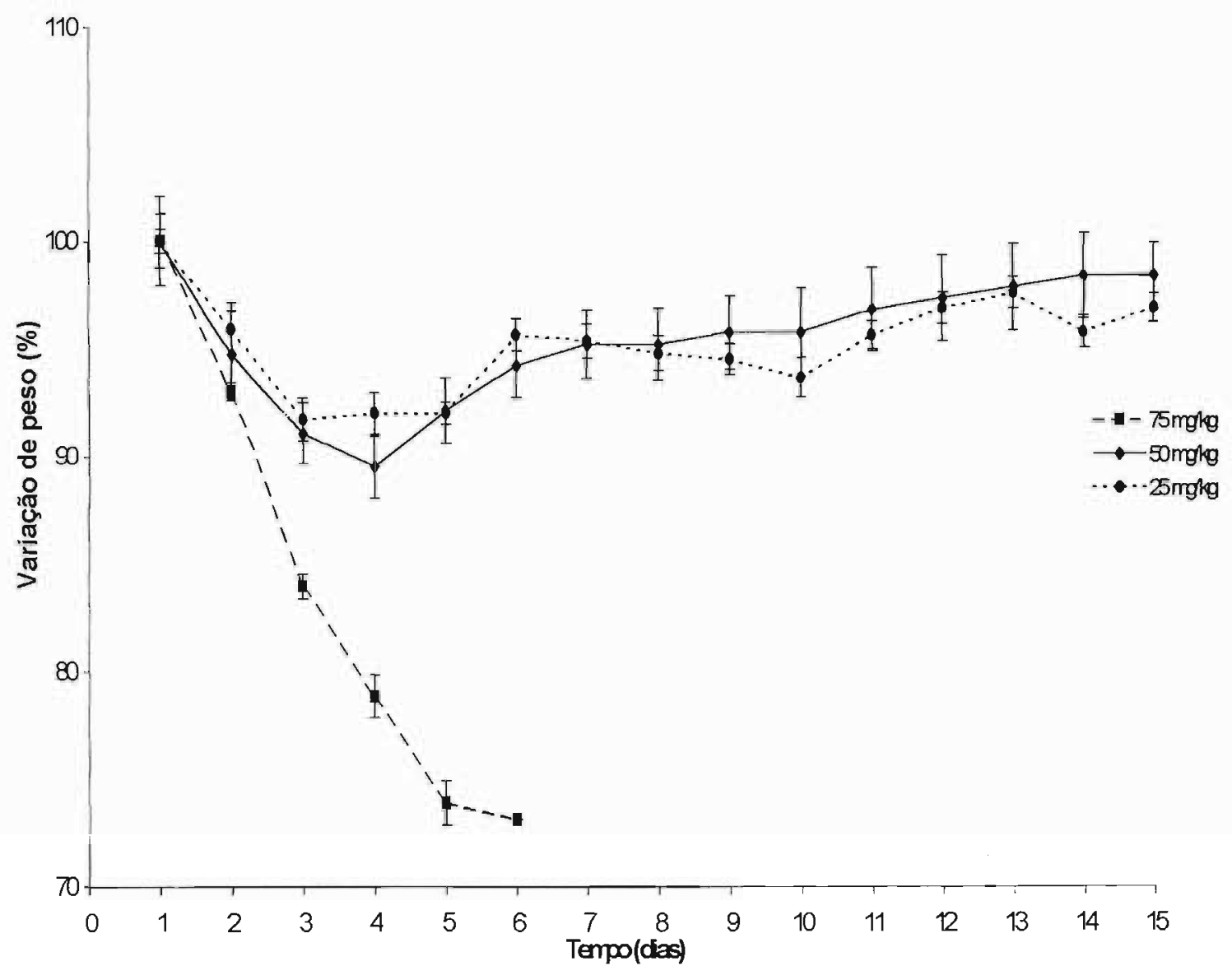

Figura 2. Curvas das médias diárias das variações de peso dos camundongos $(n=8)$ após injeção em dose única de etoposídeo em sua formulação comercial nas doses de 25,50 e 75 mg/kg. (n= 8; variação expressa em média \pm desvio médio). ( ) Morte de 1 animal no grupo. 


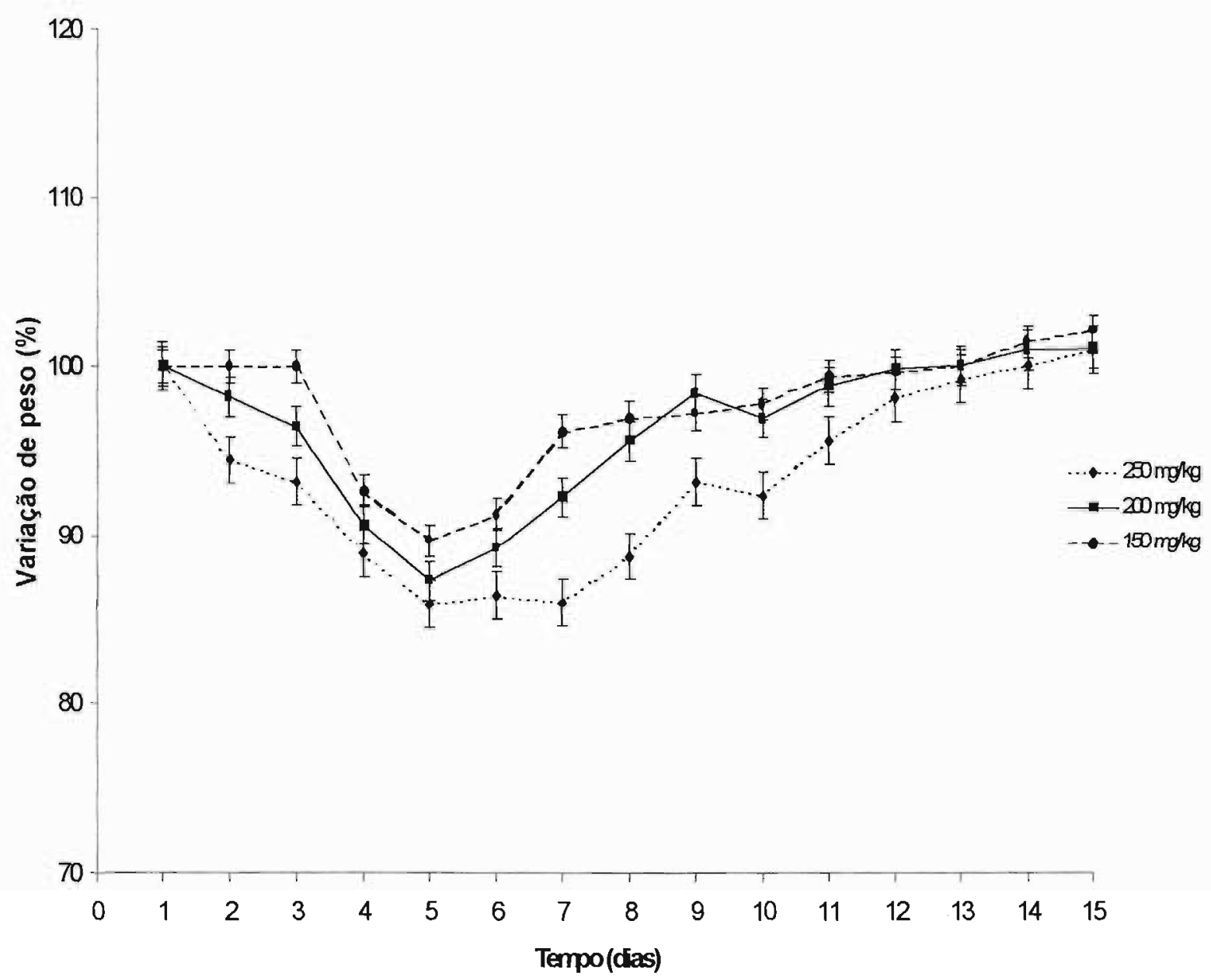

Figura 3. Curvas das médias diárias das variações de peso dos camundongos após injeção em dose única da associação LDE-oleato de etoposídeo nas doses de 150, 200 e $250 \mathrm{mg} / \mathrm{kg}$. ( $\mathrm{n}=8$; variação expressa em média \pm desvio médio).

( ) Morte de 1 animal no grupo. 


\subsubsection{Toxicidade aguda}

No mesmo modelo animal, foram determinadas as toxicidades agudas das formulações LDE, LDE-oleato de etoposídeo e etoposídeo comercial. A DL 50 para a associação LDE-oleato de etoposídeo foi cerca de 5,4 vezes superior a do etoposídeo comercial, evidenciando uma redução significativa da toxicidade do fármaco (Tabela1).

Tabela 1 - Determinação das doses letais 10,50 e 90 em camundongos fêmeas C57BL/6J, após administração por via intraperitoneal das formulações: etoposídeo comercial, LDE-oleato de etoposídeo e LDE. $(n=5)$
FORMULAÇÃO
$\mathrm{DL}(\mathrm{mg} / \mathrm{kg})^{\star}$

\begin{tabular}{lccc}
\hline & $\mathrm{DL}_{\mathbf{1 0}}$ & $\mathrm{DL}_{\mathbf{5 0}}$ & $\mathrm{DL}_{\mathbf{9 0}}$ \\
LDE-oleato de etoposídeo & 215 & 312 & 464 \\
Etoposídeo comercial & 36 & 59 & 72 \\
LDE & 400 & $>420$ & $>420$ \\
\hline
\end{tabular}

*Administração em dose única 


\subsection{ATIVIDADE ANTITUMORAL}

A atividade antitumoral das formulações LDE-oleato de etoposídeo e etoposídeo comercial foi avaliada com base na sua capacidade de retardar o crescimento do tumor de melanoma B16 implantado em camundongos e de aumentar a porcentagem de sobrevivência dos animais.

\subsubsection{Efeito sobre o crescimento do tumor de melanoma B16}

As curvas de crescimento do tumor indicam que a LDE-oleato de etoposídeo $10 \mathrm{mg} / \mathrm{kg}$ é mais eficientes em retardar a velocidade do crescimento do tumor do que o etoposídeo comercial, em mesma dosagem, e que a solução controle $(p<0,05)$, como mostrado na Figura 4. A figura mostra, no entanto, não haver diferença entre as doses de $10 \mathrm{mg} / \mathrm{Kg}$ e $50 \mathrm{mg} / \mathrm{Kg}$ da LDE-oleato de etoposídeo $(p>0,05)$. A variação de eficácia antitumoral entre as formulações é bem evidente, podendo ser vista com clareza nas figuras 5 a 8 . Tendo os animais pertencentes a todos os grupos iniciado o tratamento com massa tumoral similar (aproximadamente $0,5 \mathrm{~cm}$ ), as figuras mostram o volume tumoral no dia do término do tratamento $\left(16^{\circ}\right.$ dia) e no dia do término das observações do volume tumoral $\left(25^{\circ}\right.$ dia).

$\mathrm{Na}$ tabela 2 estão representados alguns índices de atividade antitumoral de LDE-oleato de etoposídeo 10 e $50 \mathrm{mg} / \mathrm{kg}$, etoposídeo comercial 10 $\mathrm{mg} / \mathrm{kg}$ e solução controle $(\mathrm{NaCl} 0,9 \%)$ das formulações no $17^{\circ}, 19^{\circ}, 21^{\circ}, 23^{\circ}$ e $25^{\circ}$ dia. 


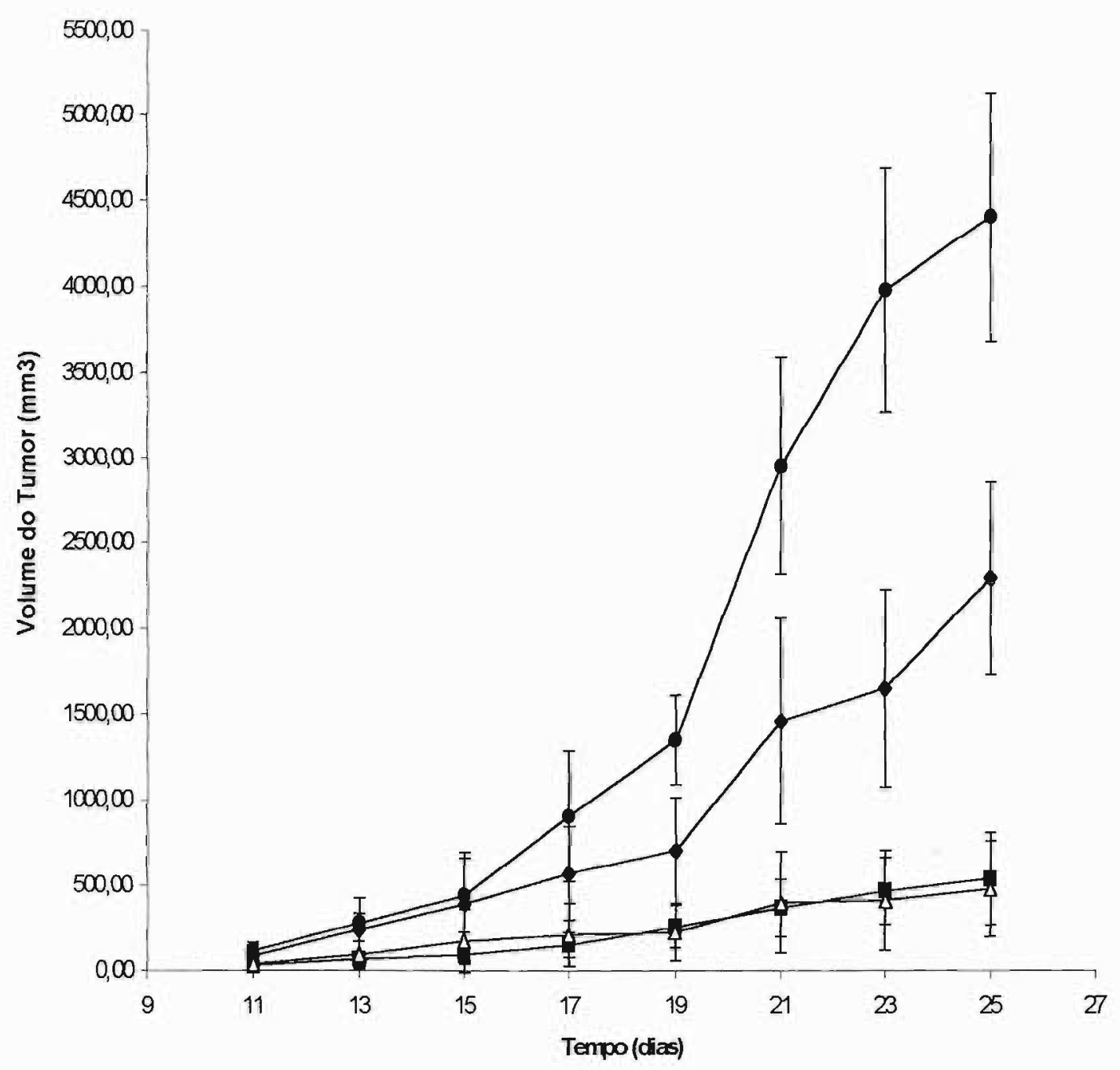

Figura 4. Crescimento da massa de tumor de melanoma B16 em grupos de camundongos tratados com as formulações de LDE-oleato de etoposideo $10 \mathrm{mg} / \mathrm{kg}$ ( $\rho$ ), LDE-oleato de etoposídeo $50 \mathrm{mg} / \mathrm{kg}$ (অ), etoposídeo comercial $10 \mathrm{mg} / \mathrm{kg}$ (블) e solução de $\mathrm{NaCl} 0,9 \%(\bullet)$. (n=15; variação expressa em média \pm desvio médio). 
Tabela 2 - Atividade antitumoral de LDE-oleato de etoposídeo (10 e 50 mg/kg) vs etoposídeo em sua formulação comercial $(10 \mathrm{mg} / \mathrm{kg})$ no modelo de melanoma B16 implantando em camundongos C57BI/6J.

\begin{tabular}{|c|c|c|c|c|c|c|c|c|c|}
\hline \multirow{2}{*}{$\begin{array}{l}\text { Fármacos e } \\
\text { controle }\end{array}$} & \multicolumn{5}{|c|}{ Média do Volume do Tumor (mm3) } & \multirow{2}{*}{$\begin{array}{c}\% \\
\text { Mortali } \\
\text { dade } \\
35^{\circ} \text { dia }\end{array}$} & \multirow{2}{*}{$\begin{array}{c}\% \\
\text { T/C } \\
19^{\circ} \text { dia }\end{array}$} & \multirow{2}{*}{$\begin{array}{c}\% \\
\text { TGl } \\
19^{\circ} \text { dia }\end{array}$} & \multirow{2}{*}{$\begin{array}{c}\text { T-C } \\
\text { (dias) }\end{array}$} \\
\hline & $\begin{array}{l}17^{\circ} \\
\text { dia }\end{array}$ & $\begin{array}{l}19^{\circ} \\
\text { dia }\end{array}$ & $\begin{array}{l}21^{\circ} \\
\text { dia }\end{array}$ & $\begin{array}{l}23^{\circ} \\
\text { dia }\end{array}$ & $\begin{array}{l}25^{\circ} \\
\text { dia }\end{array}$ & & & & \\
\hline $\mathrm{NaCl} 0,9 \%$ & 905 & 1349 & 2750 & 3976 & 4400 & 100 & - & - & - \\
\hline EC $10 \mathrm{mg} / \mathrm{kg}$ & 570 & 702 & 1459 & 1648 & 2290 & 80 & 52 & 48 & 4 \\
\hline LDE-OE $10 \mathrm{mg} / \mathrm{kg}$ & 152 & 257 & 366 & 466 & 536 & 67 & 19 & 81 & 10 \\
\hline LDE-OE 50mg/kg & 209 & 227 & 398 & 412 & 477 & 73 & 17 & 83 & 10 \\
\hline
\end{tabular}

$E C=$ Etoposídeo em sua formulação comercial

LDE-OE = Oleato de etoposídeo incorporado à LDE.

$\% \mathrm{~T} / \mathrm{C}=$ (Média da massa tumoral dos animais tratados/ Media da massa tumoral dos animais controles) $\times 100$

$\% \mathrm{TGI}=100-(\% \mathrm{~T} / \mathrm{C})$

$\mathrm{T}$ - C = Índice de retardamento na progressão do tumor (tempo médio estimado para o grupo tratado (T) e o controle (C) alcançar um tamanho predeterminado (> $750 \mathrm{mg}$ ). 

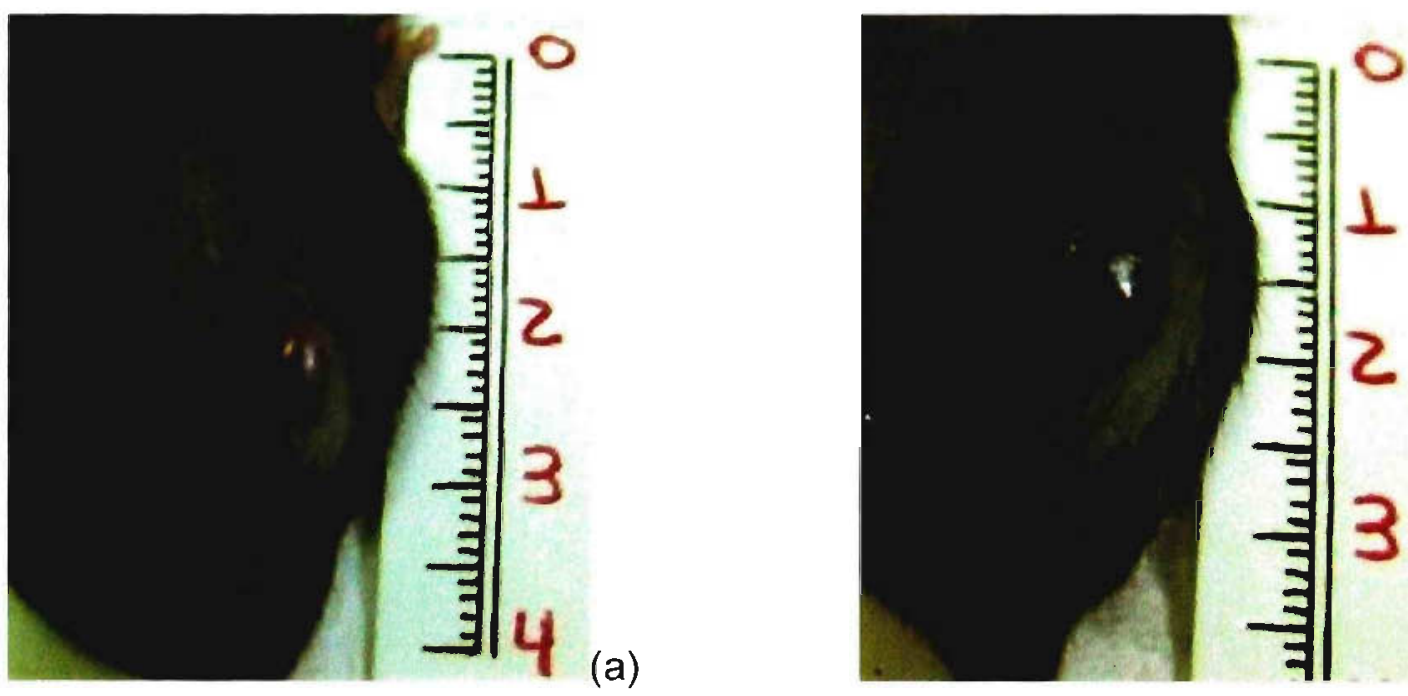

(b)

Figura 5. Volume tumoral em animal do grupo etoposídeo comercial $10 \mathrm{mg} / \mathrm{kg}$ no $16^{\circ}$ dia (a) e no $25^{\circ}$ dia (b).
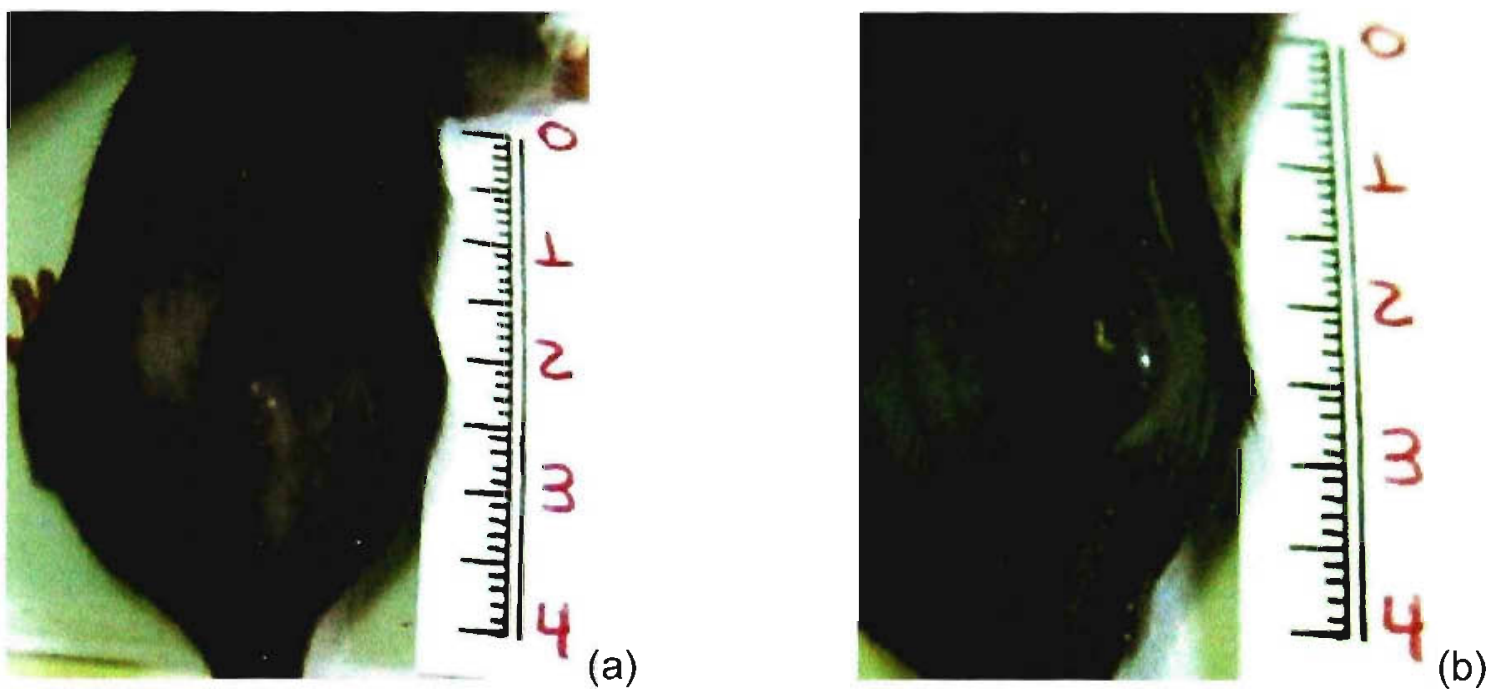

Figura 6. Volume tumoral em animal do grupo LDE-oleato de etoposídeo $10 \mathrm{mg} / \mathrm{kg} \mathrm{no} 16^{\circ}$ dia (a) e no $25^{\circ}$ dia (b) 

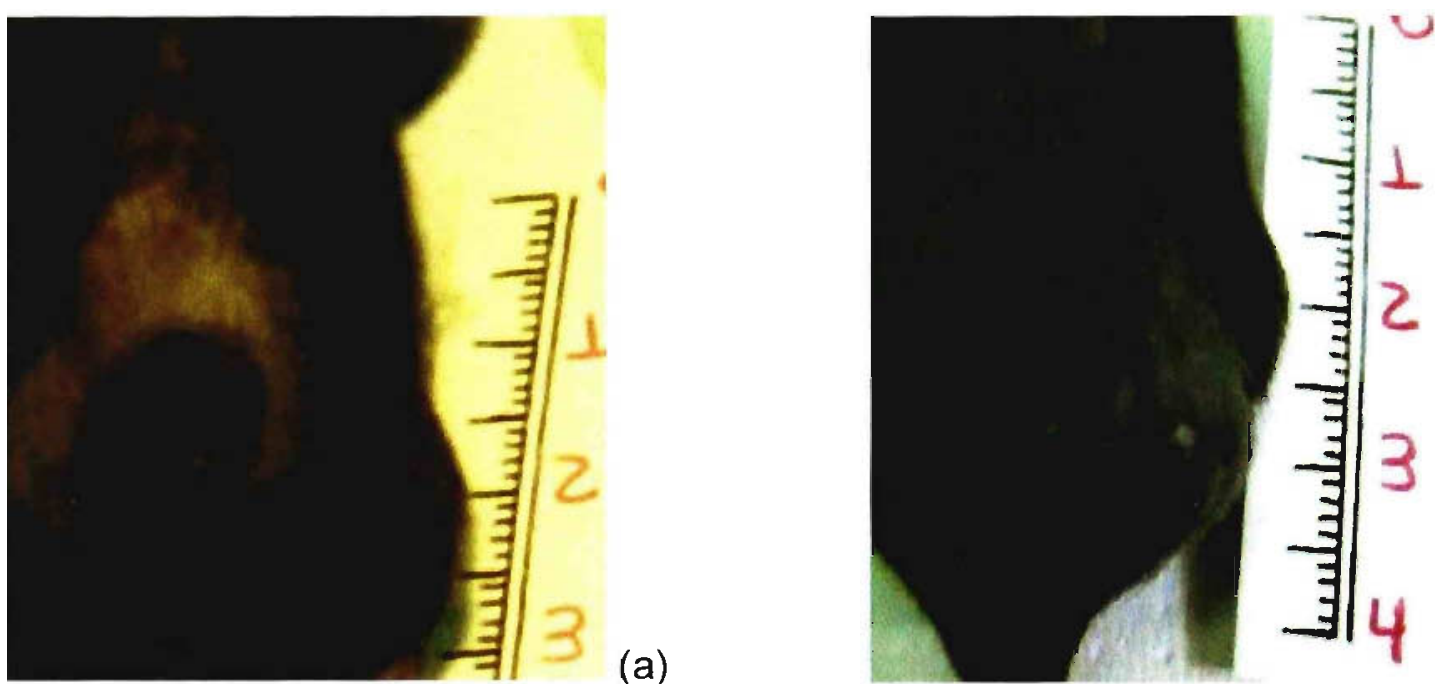

(b)

Figura 7. Volume tumoral em animal do grupo controle no $16^{\circ}$ dia (a) e no $25^{\circ}$ dia (b).

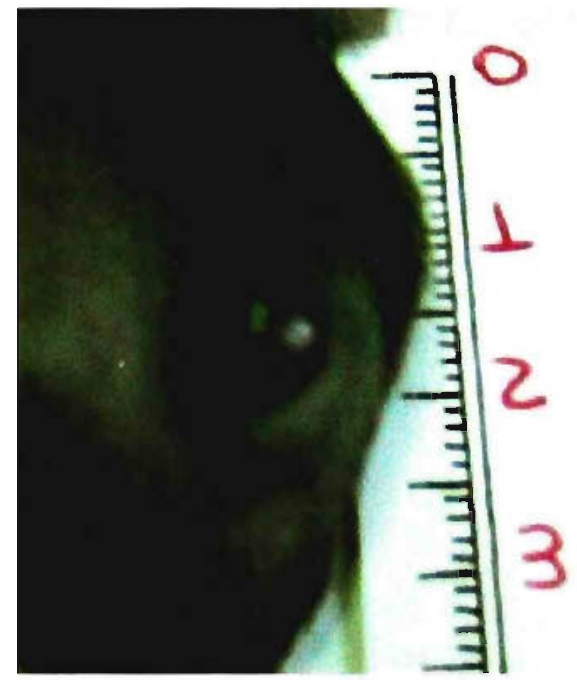

(a)

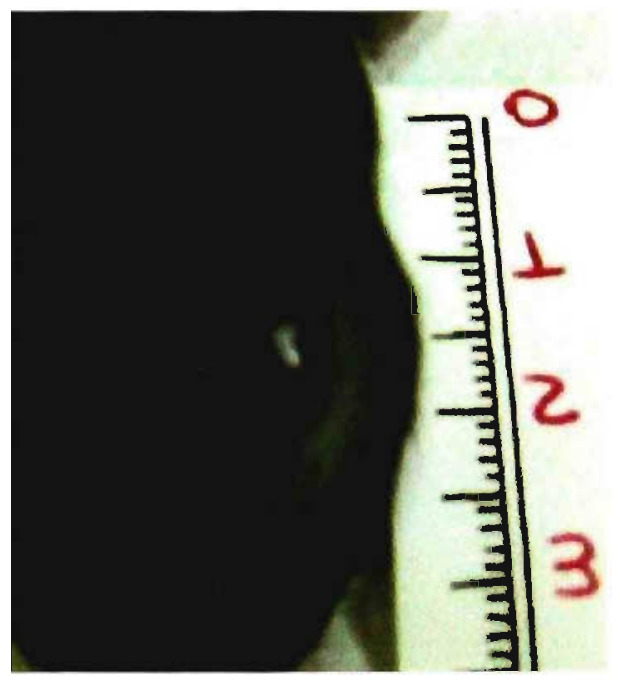

(b)

Figura 8. Volume tumoral em animal do grupo LDE-oleato de etoposideo $50 \mathrm{mg} / \mathrm{kg}$ no $16^{\circ}$ dia (a) e no $25^{\circ}$ dia (b) 


\section{2 .2 \% Sobrevivência dos animais}

A porcentagem de sobrevivência dos camundongos com implante do melanoma B16 foi avalidada no período de 45 dias.

A figura 9 representa as taxas de sobrevivência dos camundongos tratados com LDE-oleato de etoposídeo e com etoposideo comercial, em mesma dosagem de $10 \mathrm{mg} / \mathrm{kg}$. Nessa figura é mostrada a melhora do índice de sobrevivência dos animais tratados com LDE-oleato de etoposídeo em comparação aos tratados com etoposideo comercial e com solução controle ( $\mathrm{NaCl} 0,9 \%$ ). No $35^{\circ}$ dia, dia em que a porcentagem de mortalidade dos camundongos do grupo controle atingiu $100 \%$, animais tratados com etoposídeo comercial apresesentaram $20 \%$ de sobrevivência. A associação LDE-oleato de etoposídeo nas doses de 10 e 50 mg/kg, apresentou 33 e $27 \%$ de sobrevida animal, respectivamente No entanto, é demonstrada pouca variação de sobrevivência entre os camundongos tratados em ambas as dose da associação LDE-oleato de etoposídeo, quando analizado todo o período de 45 dias (figura 10). 


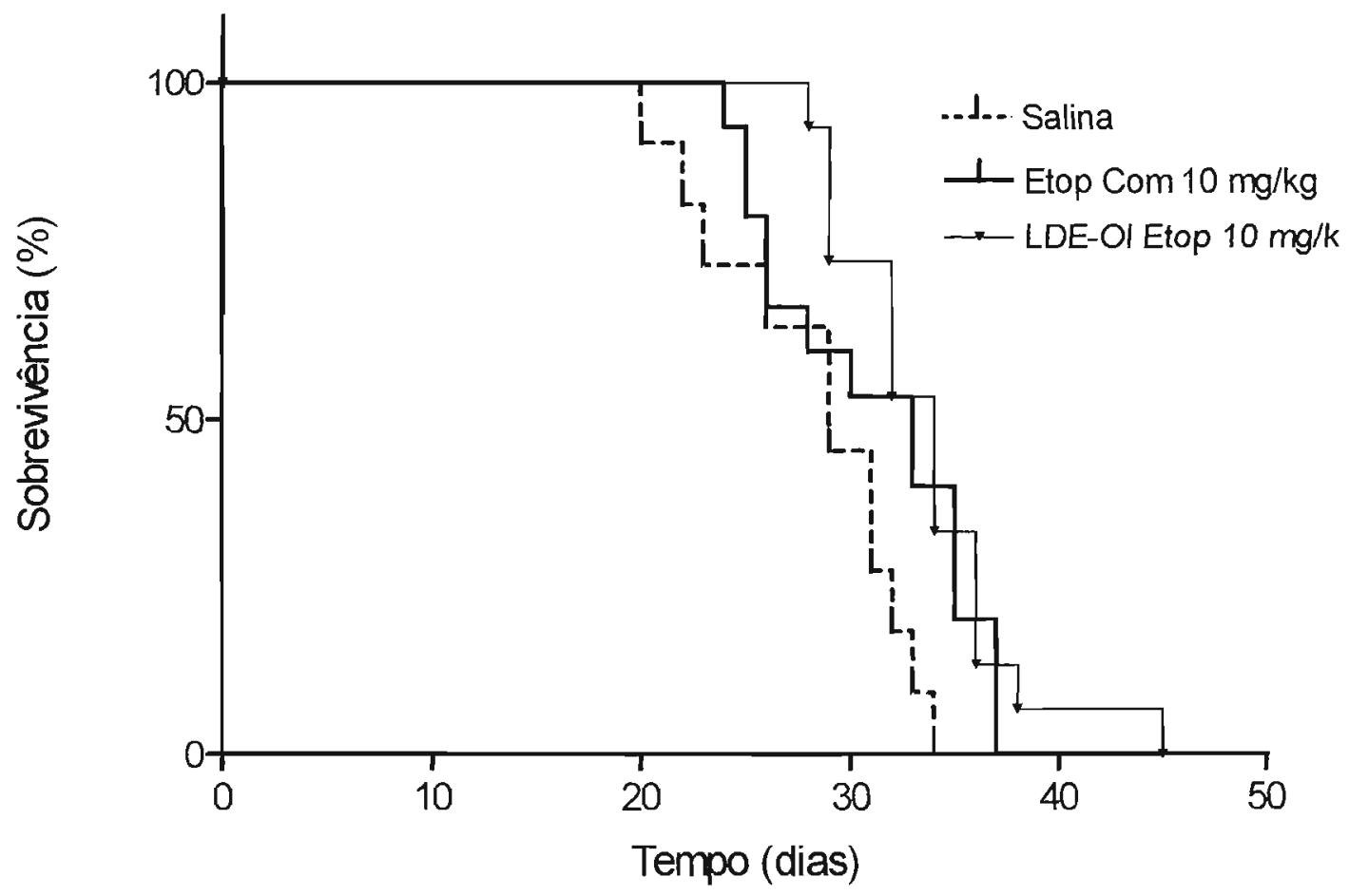

Figura 9. Porcentagem de sobrevivência dos camundongos tratados com as formulações LDE-oleato de etoposídeo e etoposídeo comercial, em mesma dosagem de $10 \mathrm{mg} / \mathrm{kg}$, e solução controle ( $\mathrm{NaCl}$ $0,9 \%)$, após inoculação de tumor de melanoma B16. $(n=15)$ 


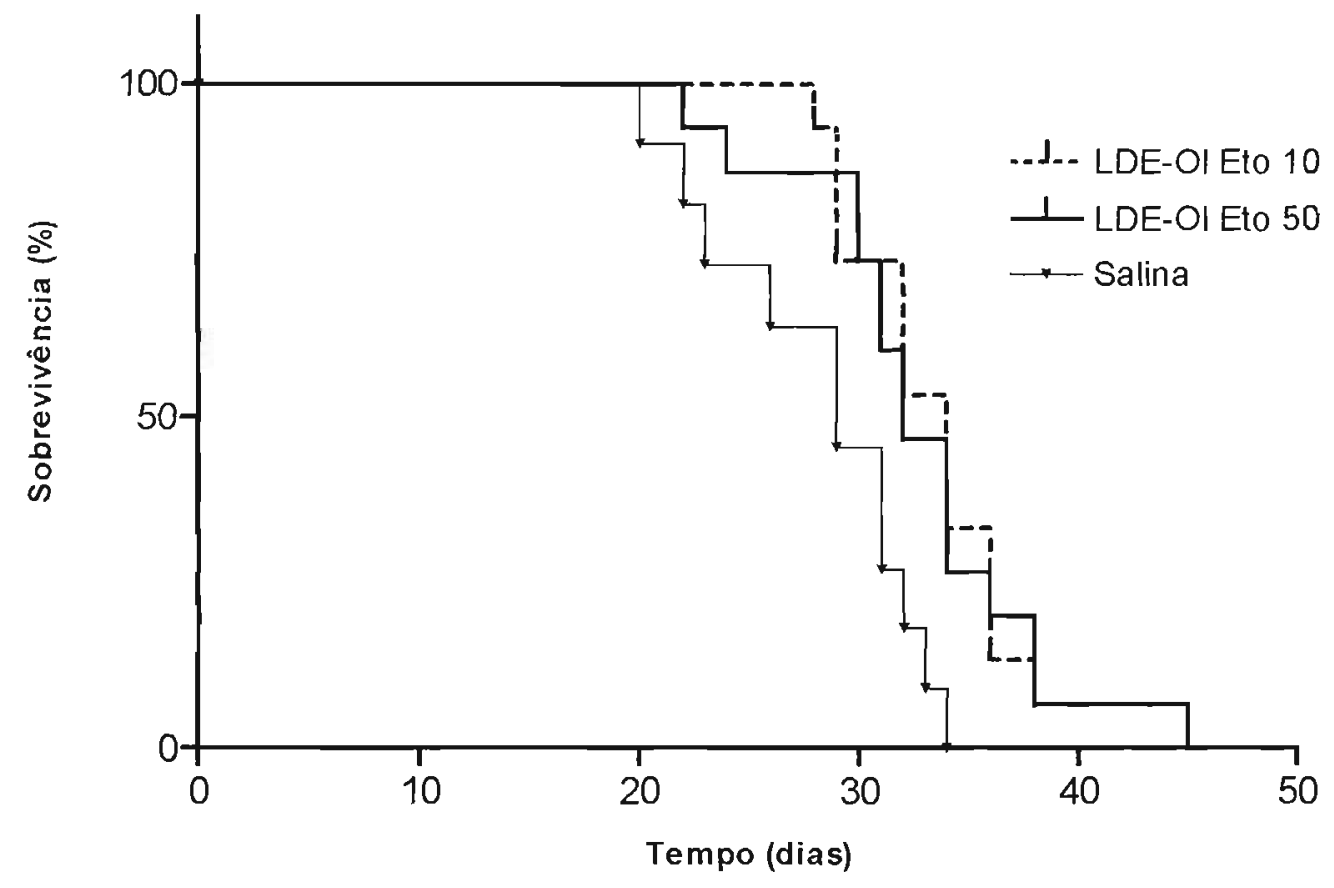

Figura 10. Porcentagem de sobrevivência entre camundongos tratados com a formulação LDE-oleato de etoposídeo, nas dosagens de 10 e $50 \mathrm{mg} / \mathrm{kg}$, e solução controle ( $\mathrm{NaCl}$ 0,9\%), após inoculação de tumor de melanoma B16. $(n=15)$ 
6. DISCUSSÃO 
Fármacos em uso clínico podem ter sua performance melhorada através de modificações em suas moléculas, ou emprego de veículos e/ou transportadores, capazes de torná-los menos tóxicos e mais ativos. Na tentativa de se aumentar o índice terapêutico dos fármacos de ação antineoplásica, tem sido tentada sistematicamente a incorporação desses à LDE.

Quando injetada na circulação, a LDE liga-se aos rLDL, presentes na superfície da membrana celular. Em grande parte das células neoplásicas, o número de rLDL está muito aumentado, permitindo aumento da concentração da LDE nesses tecidos e, conseqüentemente, do fármaco que estiver associado. Recentemente utilizou-se a LDE como transportadora do quimioterápico paclitaxel (RODRIGUES et al., 2002), sendo a citotoxicidade e a toxicidade letal da associação LDE-paclitaxel seis vezes e dez vezes menor, respectivamente, que a do paclitaxel em sua formulação comercial $\left(\right.$ Taxol $\left.^{\circledR}\right)$.

Outro quimioterápico de ação antineoplásica incorporado à LDE foi a carmustina. A associação LDE-carmustina manteve a atividade citotóxica do fármaco e foi captada via rLDL. A biodistribuição, em camundongos, e a cinética plasmática, em humanos, da LDE não foram alteradas, após a incorporação do fármaco. A associação LDE-carmustina mostrou-se com baixa ou nenhuma toxicidade em pacientes, mesmo em alta doses, indicando uma redução da toxicidade do fármaco após associação à LDE (MARANHÃO et. al., 2002; HUNGRIA et. al., 2004 ).

O fármaco utilizado neste estudo foi o etoposídeo. Pacientes fazendo uso deste fármaco têm como efeitos colaterais agudos, náuseas e vômitos. Os efeitos tardios são alopécia e mielossupressão, sendo a granulocitopenia predominante. A associação do etoposídeo à LDE foi proposta inicialmente com a 
finalidade de se obter melhora na terapêutica deste fármaco. Tendo apresentado baixa taxa de incorporação, sua estrutura foi modificada pela introdução de um grupo oleila, processo utilizado afim de torná-lo mais lipofílico. Após tal modificação, sua taxa de incorporação à LDE elevou-se de 50 para aproximadamente $98 \%$, sem alterar o efeito citotóxico. A citotoxicidade da associação LDE-oleato de etoposídeo para a linhagem celular H 292 (células não-pequenas de pulmão), foi em torno de duas vezes menor do que a formulação comercial, sendo que essa diferença é atribuída à toxicidade do veículo, na preparação comercial. Além disso, foi comprovada que a captação da associação LDE-oleato de etoposídeo é mediada via rLDL (VALDUGA et al., 2003).

Este trabalho teve como proposta dar seqüência aos estudos com o quimioterápico etoposídeo, determinando a toxicidade e eficácia antitumoral do fármaco associado à LDE. Através do estudo de toxicidade crônica pôde-se verificar aumento na DMT, assim como mais rápida recuperação do peso dos animais, quando o fármaco está associado à LDE. Segundo protocolo estabelecido por ZHANG et. al. (1997), a DMT é a dose em que não há morte ou perda de peso superior a $15 \%$ em nenhum animal do grupo.

Camundongos que receberam dose de $50 \mathrm{mg} / \mathrm{kg}$ de etoposídeo em sua formulação comercial apresentaram perda de peso inferior a 15\%, no entanto, houve três mortes nesse grupo. No grupo de animais que receberam a dose de 25 $\mathrm{mg} / \mathrm{kg}$ não houve mortes ou perda de peso superior ao limite estabelecido, sendo esta designada como a DMT do etoposídeo comercial. Em estudo realizado por MALONNE et al. (2000) a DMT encontrada para o etoposídeo comercial foi de 40 $\mathrm{mg} / \mathrm{kg}$, contudo, neste trabalho o único critério estabelecido para se avaliar a DMT 
foi a ausência de morte nos grupos, o que justificaria um valor superior ao encontrado em nosso estudo. Por outro lado, a DMT estabelecida para a associação LDE-oleato de etoposídeo foi $200 \mathrm{mg} / \mathrm{kg}$, sendo esta oito vezes superior a encontrada para o etoposídeo comercial. Isto indica que a associação do fármaco `a LDE resulta em redução da toxicidade.

Ao se analisar a perda de peso dos animais foi verificado que, no grupo LDE-oleato de etoposídeo, os animais demoravam de 8 a 9 dias para recuperarem seu peso inicial, enquanto que a maioria dos animais pertencentes ao grupo etoposídeo comercial não recuperaram seu peso durante o período de observação.

No que se refere à toxicidade aguda, foram ainda determinadas as doses letais 10, 50 e 90 da LDE-oleato de etoposídeo e etoposídeo comercial. Ao determinar as doses letais da LDE-oleato de etoposídeo e etoposídeo comercial, em linhagem de camundongo C57B//6J, foi encontrada $\mathrm{DL}_{10}$ de $36 \mathrm{mg} / \mathrm{kg}$ para etoposídeo comercial é de $215 \mathrm{mg} / \mathrm{kg}, 5,9$ vezes maior, para o fármaco associado à LDE. Dados da literatura relataram a $\mathrm{DL}_{10}$ do etoposídeo, em camundongos atímicos, como sendo 9,4 mg/kg (JENSEN et.al., 1990).

Em estudo realizado por Lee et. al. (1995) o etoposídeo foi suspenso em uma solução oleosa (iodina e etil ésteres) a fim de diminuir sua toxicidade. 0 etoposídeo em solução oleosa apresentou-se 1,24 vez menos tóxico do que o comercial. Nos experimentos com o etoposídeo associado à LDE, a associação se apresentou cerca de 5 vezes menos tóxica do que o etoposídeo comercial.

O aumento na margem de segurança do fármaco, que é refletido na diminuição de sua toxicidade, nos deu segurança para elevar a dose terapêutica no 
experimento de eficácia antitumoral. Desta forma, em posterior ensaio, foi verificada a efetividade da associação em reduzir a velocidade de crescimento do tumor, assim como em aumentar a porcentagem de sobrevivência animal, em comparação ao etoposídeo comercial.

Nesses ensaios foi utilizado um modelo de tumor murino, melanoma B16 F10, o qual tem sido muito utilizado em protocolos que avaliam o efeito de novos farmácos antineoplásicos. A escolha deve-se ao fato de se tratar de um modelo com rápida proliferação celular (GERAN et al., 1972), e por apresentar alta expressão de rLDL (VERSLUIS et al., 1996), condições favoráveis para a realização de experimentos com a LDE associada à fármacos antineoplásicos.

Não havendo na literatura critérios pré-estabelecidos para escolha do esquema posológico em modelo animal, optou-se pelo tratamento em 3 doses no $11^{\circ}, 13^{\circ}$ e $15^{\circ}$ dia após a inoculação do tumor, com intervalo de 1 dia entre as dose para que não ocorresse toxicidade cumulativa do fármaco.

As curvas de crescimento do tumor de melanoma B16 em camundongos indicaram que, as formulações de LDE-oleato de etoposídeo são mais eficientes em retardar a velocidade do crescimento tumoral do que as de etoposídeo comercial e solução controle $(p<0,05)$, resultado bem evidenciado em fotos tiradas ao longo do tratamento. No entanto, como ocorrido em experimentos anteriores realizados com os antineoplásicos daunorrubicina e paclitaxel, não houve diferença nas curvas de crescimento tumoral entre os dois níveis de dose testados de LDEoleato de etoposídeo $(p>0,05)$. Este resultado pode ser atribuído ao fato da dose de $10 \mathrm{mg} / \mathrm{kg}$ ser, efetivamente, a dose com a qual se obtém o efeito máximo. Outra explicação para a ausência de um maior efeito da dose de $50 \mathrm{mg} / \mathrm{kg}$, poderia estar 
ligado ao esquema de administração, à saturação dos rLDL em função de curto período de adminitração ou a outras variáveis das condições experimentais do presente estudo

$\mathrm{Na}$ comparação da porcentagem de sobrevivência entre camungongos tratados com ambas as formulações em mesma dosagem de $10 \mathrm{mg} / \mathrm{kg}$, houve melhora da taxa de sobrevivência dos animais tratados com a LDE-oleato de etoposídeo. Por outro lado, quando a dose foi aumentada de 10 para $50 \mathrm{mg} / \mathrm{kg}$ de LDE-oleato de etoposídeo houve, no início do tratamento, piora na taxa de sobrevivência dos animais. Após este período, as taxas de sobrevivência nas duas doses da LDE-oleato de etoposídeo se igualaram. Tendo em vista que o efeito antitumoral nas duas dosagens foi o mesmo, esta diminuição da taxa de sobrevivência na dose de $50 \mathrm{mg} / \mathrm{kg}$ pode ser devida à toxicidade da dose.

O conjunto de estudos de toxicidade e ação antitumoral realizados no presente trabalho indica claramente que a associação do oleato de etoposídeo à LDE aumenta consideravelmente o índice terapêutico do fármaco. 
7. CONCLUSÃO 
- A toxicidade da associação LDE-oleato de etoposídeo, estimada pela DMT e $D L_{50}$, é menor que a do etoposídeo comercial.

- A eficácia terapêutica da LDE-oleato de etoposídeo, estimada pelo retardardamento na velocidade de crescimento do tumor de melanoma B16F10 e aumento da taxa de sobrevida, é maior que o etoposídeo comercial.

- Tendo em vista as conclusões acima pode-se afirmar que a associação com a LDE melhora o índice terapêutico do etoposídeo. 
8. REFERÊNCIAS BIBLIOGRÁFICAS 
ADES, A.; CARVALHO, J.P.; GRAZIANI, S. R.; AMANCIO, R. F.; SOUEN, J.S.; PINOTTI, J.A.; MARANHÃO, R. C. Uptake of a cholesterol-rich emulsion by neoplasic ovarian tissues. Gynecol. Oncol., 81(1):84-87 (2001).

BASES, R.E.; KRAKOFF, I.H. Studies of serum cholesterol levels in leukemia. J. Reticul Soc., 2:8-14 (1965).

BILHEIMER, D. W. The lipoprotein receptor concep. Drugs, 36(3):55-62 (1988).

BROWN, M.S.; KOVANEN, P. T.; GOLDSTEIN, J.L. Regulation of plasma cholesterol by lipoproteins receptors. Science, 212:628-35, 1981.

CHAKRAVORTY, R.; SERKAR, S.; SEN, S.; MUKERJII, B. Human anticancer effect of podophyllum derivatives (SPG and SPI). Br. J. Cancer, 21:33-9 (1967).

MARANHÃO, R.C.; GARICOCHEA, B.; SILVE, E.L.; DORLHIAC-LLACER, P. E.; CADENA, S.M.S.; COELHO, I.J.C.; MENEGHETTI, J.C.; PILEGGI, F.J.C.; CHAMONE, D.A.F. Plasma kinetics and biodistribution of a lipid emulsion resembling low-density lipoprotein in patients with acute leukemis. Cancer Res., 54:4660-4666 (1994).

DORLHIAC-LLACER, P. E.; MARQUEZINI, M. V.; TOFFOLETTO, O.; CARNEIRO, R. C. G.; MARANHÃO, R. C.; CHAMONE, D. A. F. In vitro cytotoxicity of the LDE: daunorubicin complex in acute myelgenous leukemia blast cells. Brazil J Med Biol Res., 34:1257-1263 (2001). 
DOW, L.W.; SINKULE, J.A.; LOOK, A. T.; HORVATH, A.; EVANS, W. E. Comparative cytotoxic and cytokinetic effects of epidophyllotoxins 4'demethyllepipodophyllotoxin-9-(4,6-O-2-ethylidene- $\alpha$-D-glucopyranoside) and 4'-demethyllepipodophyllotoxin-9-(4,6-O-2-thenylidene- $\beta$-D-glucopyranoside) and their metabolites on human leukaemic lymphoblast. Cancer Res., 43:5699706 (1983).

FILIPOWSKA D.; FILIPOWSKI T.; MORELOWSKA B.; KAZANOWSKA W.; LAUDANSKI, T.; LAPINJOKI,S.; AKERLUND,M.; BREEZE, A. Treatment of cancer patients with a low-density-lipoprotein delivery vehicle containing a cytotoxic drug. Cancer Chemother. Pharmacol., 29:396-400 (1992).

FREIREICH, E.J.; GERAN, E.A.; RALL, D.P. Quantitative comparison of toxicity of anti-cancer agents in mouse, rat, dog, monkey and man. Cancer Chemother. Rep., 50:219-245 (1996).

GABIZON, A; GOREN, D.; FUKD, Z.; MESHORER, A.; BARENHOLZ, Y. Superior therapeutic actvivity of liposome- associated adriamycin in a murine metastatic tumor model. Br. J. Cancer., 51:681-9 (1985).

GAL, D.; OHASHI, M.; MACDONALD, P.C.; BUCHSBAUM, H.J.; SIMPSON, E.R. Low-density lipoprotein as a potential vehicle for chemotherapeutic agents and radionucleotides in the management of gynecologic neoplasms. Am. J. Obstet. Gynecol., 139:877-85 (1981). 
GERAN, R.I.; GREENBERG, N.H.; MACDONALD, M.M.; SCHUMACHER, A.M.; ABBOTT, B.J. Protocols for screening chemical agents and natural products against animal tumors and other biological systems. 3.ed., Bethesda, Maryland, $47-51(1972)$.

GOODMAN, L.S.; GILMAM, A. The bases of pharcacologic, $10^{\mathrm{a}} \mathrm{Ed}$., Rio de Janeiro: McGraw-Hill Interamericana editores (2001).

GOLDSTEIN, J.L.; BROWN, M.S.; ANDERSON, R.G.W.; RUSSEL, D.W.; SCHNEIDER, W.J. Receptor-mediated andocytosis: concepts emerging from the LDL receptor system. Ann Ver. Cell Biol., 1:1-39 (1985).

GRAZIANI, S.R; IGREJA, F.A.F.; HEGG, R.; MENEGHETTI, C.; BRANDIZZI, L.I.; BARBOSA, R.; AMÂNCIO, F.R.; PINOTTI, J.A.; MARANHÃO, R.C. Uptake of a cholesterol rich emulsion by breast cancer. Ginecologic Oncology, 85:493-497 (2002).

GREENSPAN, E.; LEITER, J.; SHEAR, M. Effect of $\alpha$-peltatin, $\beta$-peltatin and podoplyllotoxin on lynfoma and other transplanted tumors. J. Natl. Cancer Institut, 10:1295-332 (1950).

HIRATA, R. D. C. Efeitos da apolipoproteína B sobre o metabolismo lipídico através da utilização de emulsões semelhantes a fração lipídica da LDL. São Paulo, 
1991. Tese (Doutorado) - Faculdade de Ciências Farmacêuticas, Universidade de São Paulo.

HIRATA, R.D.; HIRATA, M.H.; MESQUITA, C.H.; CESAR, T.B.; MARANHÃO, R.C. Effects of apolipoprotein B-100 on the metabolism of a lipid microemulsion model in rats. Biochim.Biophys. Acta, 1437(1):53-62 (1999).

HO, Y.K.; SMITH, G.L.; BROWN, M.S.; GOLDSTEIN, J.L. Low-density lipoprotein (LDL) receptor activity in human acute myelogenous leukemia cells. Blood, 52:1099-1114 (1978).

HUNGRIA, V.T.M.; CHIATTONE, C.S.; BARROS, J.C.; LATRILHA, M.C.; PILEGGI, F.; CHAMONE, D.A. F.; MARANHÃO, R.C. Plasma lipids and apolipoproteins in multiple myeloma patients. Blood, 86: 836 (1995).

HUNGRIA, V.T.M.; LATRILHA, M.C.; RODRIGUES, D.G.; BYDLOWSKI, S.P.; CHIATTONE, C.S.; MARANHÃO, R.C. Metabolism of a cholesterol-rich microemulsion (LDE) in patients with multiple myeloma and a preliminary clinical study of LDE as a drug vehicle for treatment of the disease. Cancer Chemother. Farmacol. 53:51-60 (2004).

JENSEN, B. B; ROED, H.; SKOVSGAARD, T.; FRICHE, E.; VINDELOV, L.; HANSEN, H. H.; SPANG-THOMSEN, L. Antitumor activity of the two epidophyllotoxin derivatives VP-16 and VM-26 in preclinical systems: a 
comparison of in vitro and in vivo drug evaluation. Cancer Chemother. Pharmacol., 27:194-8 (1990).

JUNGHANS, R.P.; SGOUROS, G.; SCHEINBERG, D. A antibory-based immunotherapies for câncer. Cancer Chemother. Biother., 655-7 (1996).

KAN, P.; CHEN, Z.; LEE, C.; CHU, I. Development of nonionic surfactant/phospholipid o/w emulsion as a paclitaxel delivery system. J. Contolled Release, 1990.

KAWINKY, D.; SINKULE, J.; FRIDLAND, J. Comparison of DNA inhibitory effects of VP -16 and its two isomeres in cultured human leukemia cells. Proc. Am. Ass. Cancer Res., 23:198 (1982).

KELLER-JUSTIN, C.; KUHN, M.; VON WARTBURG, A. Synthesis and antimiotic activity of glycosidic lignan derivatives related to podophyllotoxin. J. Med. Chem., 14:936-40 (1971).

KING, L.; SULLIVAN, M. The similarity of the effect of podophyllotoxin and colchicines and their use in the treatmant of condylomata acuminata. Scienc, $104: 244-5(1946)$

KOROLKOVAS, A. Essentials of Medicinal Chemistry, $2^{\text {nd }}$ edition, John Wiley \& Sons, USA, 1988. 
LEE, J. S.; TAKAHASHI, T.; HAGIWARA, A.; YONEYAMA, C.; ITOH, M.; SASABE, T.; MURANISHI, S.; TASHIMA, S. Safety and efficacy of intrapentoneal injection of etoposide in oil suspension in mice with peritoneal carcinomatosis. Cancer Chemother. Pharmacol., 36:211-216 (1995).

LUNDBERG, B. Preparation of drug-low density lipoprotein complexes for delivery of antitumoral grugs via de low density lipoprotein pathway. Cancer Res., 47:41058 (1987)

LUNDBERG B. Preparation of drug-carrier emulsions stabilized with phosphatidylcholine-surfactant mixture. J.Pharm.Sci., 83(1):72-75 (1994).

MALLONE, H., FARINELLE, S.; DECAESTECKER, C.; GORDOWER, L.; FONTAINE, J.; CHAMINADE, F.; SAUCIER, J-M.; ATASSI, G.; KISS, R. In vitro and in vivo fharmacological characterizations of the antitumor properties of two new olivacine derivatives, S16020-2 and S30972-1. Clinical Cancer Research. $6: 3774-82(2000)$

MASQUELIER M.; VITOLS S.; PETERSON C. Low-density lipoprotein as a carrier of antitumoral drugs: in vivo fate of drug-human low-density lipoprotein complexes in mice. Cancer Res., 46(8):3842-3847, 1986. 
MASQUELIER M.; VITOLS S.; PALSSON M.; MARS U. LARSON B.S.; PETERSON C.O. Low Density lipoprotein as a carrier of cytostatics in cancer chemotherapy: study fo stability of drug-carrier complexes in blood. J. Drug Target, 8(3):155-164 (2000).

MARANHÃO, R. C.; TERYAC, A. M.; REDGRAVE, T. G. Effects of cholesterol content on metabolism of protein-free emulsion models of lipoprotein. Biochem. Biophys. Acta, 875:247-55 (1986).

MARANHÃO, R.C.; CESAR, T.B.; PEDROSO-MARIANI, S.R.; HIRATA, M.H.; MESQUITA, C.H. Metabolic behavior in rats of a nonprotein microemulsion resembling low-density lipoprotein. Lipids, 28(8):691-696 (1993).

MARANHÃO, R.C.; GARICOCHEA, B.; SILVA, E. L.; LLACER, P. D.; CADENA, S. M. S.; COELho, I. J. C.; MENEGHETTI, J. C.; PILEGGI, F. J. C.; CHAMONE, D. A. F. Plasma kinetics and biodistribution of a lipid emulsion resembling lowdensity lipoprotein in patiens with acute leukemia. Cancer Res., 54:4660-66 (1994).

MARANHÃO, R.C.; ROLAND, I.A.; TOFFOLETTO, O.; RAMIRES, J.A.; GOLÇALVES, R.P.; MESQUITA, C.H.; PILEGGI, F.J.C. Plasma kinetics behavior in hyperlipidemic subjects of a lipidic microemulsion that binds to low density lipoprotein receptors. Lipids, 32(6):627-633 (1997). 
Association of carmustine with a lipid emulsion: in vitro, in vivo and preliminary studies in cancer patiens. Cancer Chemother. Pharmacol, 49(6):487-98 (2002).

MASQUELIER, M.; VITOLS, S.; PETERSON, C. Low density lipoprotein as a carrier of antitumoral grugs: in vivo fate of drug-human low-density lipoprotein complexes in mice. Cancer Res., 46:3842-7 (1986).

NYDEGGER U.E. B. Serum lipoprotein levels in patients with cancer. Cancer Res. 32(8):1756-1760 (1972).

PETER, I.; SLEVIN, M. The clinical pharmacology of etoposde and teniposide. Clinical Pharmacokinetic, 12:223-252 (1987).

PLOWMAN J.; DYKER D.J.; HOLLINGSHEAD M.; SIMPSON-HERREN; ALLEY M.C. Human tumor xenograft models in $\mathrm{NCl}$ development, in Anticancer Drug Development: Preclinical Screening, Clinical Trials and Approval (B.A. Teicher ed.) Humana Press, Totowa, New Jersey, 101-125 (1997).

REDGRAVE, T.G.; MARANHAO, R.C. Metabolism of protein-free lipid emulsion models of chylomicrons in rats. Biochimi. Biophys. Acta, 835:104-12 (1985).

RODRIGUES, D. G.; COVOLAN, C. C.; CORADI, S. T.; BARBOZA, R.; MARANHÃO, R. C. Use of a cholesterol-rich emulsion that binds to low-density lipoprotein receptors as a vehicle for paclitaxel. J. Pharm. and Pharmacol., 54:765 (2002). 
MARANHÄO, R. C. Use of a cholesterol-rich emulsion that binds to low-density lipoprotein receptors as a vehicle for paclitaxel. J. Pharm. and Pharmacol., $54: 765$ (2002).

RUDLING, M.J.; COLLINS, V.P.; PETERSON, C.O. Delivery of aclacinomycin A to human glioma cells in vitro by the low-density lipoprotein pathway. Cancer Res., 43:4660-5 (1983).

RUDLING, M. J.; STAHLE, L.; PETERSON, C. O.; SKOOG, L. Content of low-density lipoprotein receptors in breast cancer tissue related to survival of patients. $B r$. Med.J., 292: 580 (1986).

RUDLING, M.J.; ANGELIN, B.; PETERSON, C.O.; COLLINS, V.P. Low-density lipoprotein receptor activity in human intracranial tumours and its relation to the cholesterol requirement. Cancer Res., 50: 483-87 (1990).

SENGUPTA, S.; VELPANDIAN, T.; SAPRA, P.; SANYAL, M.; GUPTA, S. K. Etoposide encapsulated long circulating lipossomes: improved antitumour efficacy with reduced adverse effects. Naunyn Schmeide-berg's Arch Pharmacol., 358 (1998).

SENGUPTA, S.; TYAGI, P.; CHANDRA, S; KOCHUPILLAI, V.; GUPTA, S. K.. Encapsulation in cationic liposomes enthances antimour efficacy and reduces the toxicity of etoposide, a topoisomerase II inhibitor. Pharmacology., 760 
(2000).

SMIDT, P.C.; VAN BERKEL, T.J.C. Prolonged serum half-life of antineoplasic drugs by incorporation into the low density lipoprotein. Cancer Res., 50:7476-82 (1990).

TOKUI, T.; TAKATORI, T.; SHINOZABI, N.; ISHIGAMI, M.; SHIRAISHI, A.; TOSHIHIKO, I.; TSURUO, T. Delivery and cytotoxity of RS-1541 in St-4 human gastric cancer cells in vitro by the low density lipoprotein pathway. Cancer Chemother pharmacol., 36:1-6 (1995).

VAITKEVICIUS, V.K.; REED, M.L. Clinical studies with podophyllin compounds SPI77 (NSC-72274) and SPG-837 (42076). Cancer Chemother. Reports., 50:565$71(1966)$.

VALLABHAJOSULA, S.; GILBERT, H.S.; GOLDSMITH, S. J.; PAIDI, M. P.; HANNA, M.M.; GINSBERG, H.N. Low-density lipoprotein (LDL) distribution shown by technetium ${ }^{99 m}$-LDL imaging in patients with mieloproliferativa diseases. Ann. Inter. Med., 110:4600-5 (1989).

VAldugA, C. J.; FERNANDES, D. C.; LO PRETE, A. C.; AZEVEDO, C. H. M.; RODRIGUES, D. G.; MARANHÄO, R. C. Use of a Cholesterol-Rich Microemulsion that Binds to Low-Density Lipoprotein Receptors as Vehicle for Etoposide, J. Pharm. Pharmacol.,55:1615-1622 (2004). 
VERSLUIS, A.J.; GEEL, P.J.; OPPELAAR, H.; BERKEL, T.J.C.; BIJSTERBOSCH, M.K. Receptor-mediated uptake of low-density lipiprotein by B16 melanoma cells in vitro and in vivo in mice. British J. of Cancer., 74: 525-532 (1996).

VITOLS, S.; SÖDERBERG-REID, K.; MASQUELIER, M.; SJÖSTRÖM, B.; PETERSON, C. Low Lensity Lipoprotein for Delivery of a Water-Insoluble Akylating Agent to Malignant Cells. In vitro and in vivo studies of a DrugLipoprotein Complex. Br. J. Cancer., $62: 724$ (1990)a

VITOLS, S.; ANGELIN, B.; ERICSSON, S.; GAHRTON, G.; JULIUSSON, G.; MASQUELIER, M.; PAUL, C.; PETERSON, C.; RUDLING, M.; SÖDERBERGREID, K.; TIDEFELT, U. Uptake of Low Density Lipoproteins by Human Leukemic Cells in vivo: Relation to Plasma Lipoprotein Levels and Possible Relevance for Selective Chemotherapy. Proc. Natl. Acad. USA. 87: 2598 (1990)b

VITOLS, S.; PETERSON,C.; LARSSON, O.; HOLM, P.; ABERG, B. Elevated uptake of low density lipoproteins by human lung cancer tissue in vivo. Cancer Res. 52:6244-7(1992).

ZHANG, X.; BURT, H.M.; MANGOLD, G.; DEXTER, D.; HOFF, D.V.; MAYER, L.; HUNTER, W. Anti-tumor efficacy and biodistribution of intravenous polymeric micellar paclitaxel. Anti-cancer Drugs, 8:696-701 (1997). 